\title{
Juvenile dermatomyositis: latest advances
}

Qiong Wu MBBS BSc ${ }^{1}$, Lucy R Wedderburn BA FRCP PhD ${ }^{1,2,3}$, Liza J McCann FRCPCH BSc MMedSc ${ }^{*}$

1. Infection, Inflammation and Rheumatology Section, University College London Great Ormond Street Institute of Child Health, 30 Guilford Street, London, WC1N 1EH, United Kingdom

2. Paediatric Rheumatology Department, Great Ormond Street Hospital for Children NHS Foundation Trust, Great Ormond Street, London, WC1N 3JH, United Kingdom

3. NIHR Biomedical Research Centre at Great Ormond Street Hospital, Great Ormond Street, London, WC1N 3JH, United Kingdom

4. Paediatric Rheumatology Department, Alder Hey Children's NHS Foundation Trust, Eaton Road, Liverpool, L12 2AP, United Kingdom

${ }^{*}$ Corresponding author

Qiong Wu; Email: qiong.wu@nhs.net; Telephone: +44 207905 2391; Fax: +44 207905 2882

Lucy R Wedderburn; Email: I.wedderburn@ucl.ac.uk; Telephone: +44 207905 2391; Fax: +442079052882

Liza J McCann; Email: Liza.McCann@alderhey.nhs.uk; Telephone: +44 151228 4811; Fax: +441512525929

Word count: Text $=6075$ words + references $(3,064$ words $)=9,679$ 


\section{ABSTRACT}

Registries and biobanks in juvenile dermatomyositis have generated statistical power to help understand pathogenesis and determine treatment and long-term outcomes in this rare and heterogeneous disease. Genotype, autoantibodies, muscle histology and early clinical features may predict prognosis and guide personalised treatment. While corticosteroids and disease modifying anti-rheumatic drugs improve outcomes, there remain children who experience refractory disease. Ongoing research into the aberrant immune response and novel biological targets is necessary. Best practice guidelines promote prompt stepwise treatment and there is growing appreciation of the role of exercise in improving prognosis. Validated tools standardise assessment of disease activity and damage in musculoskeletal, mucocutaneous, pulmonary, cardiac, gastrointestinal and endocrine systems. Recently, an internationally agreed dataset for juvenile dermatomyositis has been defined for clinical practice and incorporation into registries. In the future, with bigger datasets, statistical models may guide stratification for personalised medicine and discern the most relevant outcome markers for research.

\section{Key Words}

- Juvenile Dermatomyositis

- Idiopathic Inflammatory Myopathy

- Immunogenetics

- Myositis autoantibodies

- Immunohistopathology

- Biomarkers

- Treatments

- Outcome measurement tools

- Registries 


\section{[A] Introduction}

Juvenile dermatomyositis (JDM) is a rare childhood autoimmune condition characterised by inflammation of small vessels within the skin, muscle and major organs. Prognosis is variable, ranging from monocyclic disease to chronic illness extending into adulthood with substantial complications (1). There is increasing emphasis on early aggressive treatment to improve long-term outcomes. However, response to drug therapies is unpredictable and many drugs have adverse effects. For a 'treat to target' approach, it is important to understand the underlying disease pathogenesis. Mounting evidence suggests genotype, autoantibody status and muscle histology can provide biomarkers to help guide personalised treatments.

\section{[A] Pathogenesis}

\section{[B] Genetics}

Until recently, small patient numbers and low statistical power have hampered research into the genetic contribution of JDM. The international genetics consortium in myositis (MYOGEN) has expedited international multicentre DNA sample and clinical data collection. MYOGEN recently completed the first genome-wide analysis of idiopathic inflammatory myopathies including children with JDM (2). Risk and protective alleles for JDM have been identified within the human leukocyte region (HLA), cytokine genes and lymphocyte signaling genes (Table 1). Notably, certain alleles are associated with more severe disease outcomes, such as progression to calcinosis and ulceration.

\section{[B] Autoantibodies}

Autoantibodies are found in greater than $60 \%$ of children with JDM (5). Autoantibodies are classified into myositis-specific autoantibodies (specific to myositis) and myositis-associated antibodies (present in various autoimmune diseases). Each child typically carries a single myositis-specific antibody (5) and children bearing the same antibody often share similar 
clinical features and long-term prognoses (Table 2). Certain JDM risk alleles are associated with development of specific autoantibodies $(3,4)$, suggesting there might be distinct genetic/serotypic JDM subsets exhibiting discrete disease trajectories.

\section{[B] Immunohistopathology}

Figure 1 summarises findings from studies to date exploring the humoral and cell mediated immune mechanisms precipitating muscle damage in JDM. Muscle biopsy remains important in the diagnosis of JDM, and many of the changes illustrated in Figure 1 can be detected on biopsy. A validated tool has been developed to quantify and score the histological severity of biopsies (9) with mounting interest in using this to predict disease course. Table 3 details a number of histological features and correlation with disease phenotype. Ultimately, the most powerful predictor of clinical outcome is likely to be a composite measure combining genotype, autoantibody status and muscle histology score. This is illustrated in a recent study that revealed histological severity predicted increased risk of remaining on treatment, but anti-Mi-2 autoantibody provided a protective effect. Children carrying this antibody were more likely to enter drug-free remission despite having severe disease marked on muscle biopsy (6).

\section{[B] Environment}

It is possible that a number of environmental factors disrupt the immune system of genetically susceptible children to trigger onset or influence disease course in JDM. Many children suffer from infection prior to disease onset (12) and infection within six months of illness onset increases risk of a polycyclic, rather than monocyclic, disease course (13). Gene expression profiling has revealed a prominent type I interferon-signature in JDM muscle that could be in keeping with viral exposure (14). Greater ultraviolet light exposure in boys one month prior to diagnosis increases risk of a chronic, compared to polycyclic, disease course (13). Uncovering environmental triggers could improve understanding of the complex dysregulated immune response of JDM. 


\section{[A] Treatment}

To date, very few randomised controlled trials have been possible in JDM due to disease rarity, hetereogeneity and lack of standardised tools to measure clinical outcomes.

Treatment decisions have been largely based on clinicians' experiences, and vary between centres. There is an ongoing duty to foster international collaborations to maximise basic science, translational and clinical research to find the best drug for each child. Parallel to developing personalised drug therapies, there is growing appreciation of the role of exercise in the management of JDM and the importance of a multidisciplinary team to help children achieve their potential in their school, home and social lives. Early intensive physiotherapy, occupational therapy, podiatry and psychology input are essential in finding ways to allow children to adapt to impairments associated with disease activity or damage, and to enable regain of functional status once in remission.

\section{[B] Guidelines}

The Single Hub and Access point for Pediatric Rheumatology in Europe (SHARE) is an initiative to optimise treatment regimens for children with rheumatological conditions. SHARE recently published best practice guidelines for the investigation and treatment of JDM derived from a validated systematic literature review and consensus meetings with experienced paediatric rheumatologists. Based on these recommendations, a flow chart (15) was established for the treatment of JDM (Figure 2).

The Children's Arthritis and Rheumatology Research Alliance (CARRA), a network of Paediatric Rheumatologists in North America, has also described three initial Consensus Treatment Plans (CTPs) $(16,17)$ for the treatment of moderately severe JDM based on expert opinion (Figure 3). The concept of Consensus Treatment Plans (CTPs) is to limit 
treatment practice variation to enable researchers to develop comparative effectiveness studies. This is particularly important in rare diseases where evidence is limited and randomised controlled trials are not possible due to small patient numbers. CARRA have recently extended CTPs in JDM to include treatment of persistent skin rash and treatment of skin predominant disease $(18,19)$.

\section{Recent studies}

Table 4 summarises the available evidence for drugs commonly used in the treatment of JDM, highlighting the sparsity of evidence on which clinical practice is based.

\section{[B] Current practice}

A survey revealed the majority of North American paediatric rheumatologists use corticosteroids with methotrexate for 'typical' JDM cases, although route and pattern of corticosteroid use varies (21). Respondents stated a tendency to add intravenous immunoglobulin (IVIG) in severe or refractory cases or those with marked cutaneous manifestations. Hydroxychloroquine is chosen for children with mild disease or whose main symptom is rash. Cyclophosphamide is principally reserved for children with ulceration or lung disease (22). Similarly, a survey in the United Kingdom and Ireland has shown that corticosteroids and methotrexate are often chosen as first line therapy, while cyclophosphamide is used in severe disease, systemic involvement or cutaneous ulceration (23). A cohort study collecting data between 1980 and 2004 revealed that while European children were more frequently managed with high-dose intravenous methylprednisolone, ciclosporin, cyclophosphamide and azathioprine, Latin American children with similar clinical features, often received methotrexate and hydroxychloroquine (24). This study documented a change in practice over time with increased use of intravenous methylprednisolone and second-line drugs. Subsequently, a randomised controlled trial has clearly demonstrated that addition of methotrexate or ciclosporin achieved better disease control than corticosteroids 
alone. Fewer adverse effects were seen with methotrexate compared to ciclosporin, supporting the usual practice of using prednisolone and methotrexate as first line treatment (25) (Table 4, Figure 2, Figure 3).

There has been an increasing focus on early aggressive treatment, with prompt stepwise use of medications to achieve timely remission and reduce risk of complications from disease and long-term drug toxicity (26). A recent survey in North America revealed clinicians are selecting various biologics for recalcitrant disease (20) including rituximab (most popular), abatacept, TNFa blockade, and tocilizumab. A randomised placebo phase design trial of rituximab in adults and children with dermatomyositis failed to reach primary or secondary endpoints, but the overall response rate, steroid-sparing effect and re-treatment response suggested that rituximab is efficacious for both muscle and skin disease $(27,28)$. Further studies are essential to compare the safety and efficacy of these biological agents (29-31).

\section{[B] Adjunctive treatments}

Children are taught to apply high-factor sunscreen daily as ultraviolet light can trigger JDM flares (15). Long-term corticosteroids are associated with a number of complications, and children may be co-prescribed calcium and vitamin D to reduce risk of osteoporosis (32) and gastro-protective cover to reduce risk of gastrointestinal bleeding and perforation (8).

\section{[B] Physiotherapy}

It has been suggested that exercise might be able to attenuate chronic systemic inflammation underlying pathogenesis of JDM (33). Microvascular disturbances within the muscle might reduce perfusion during exercise (34), leading to submaximal exercise capacity, lower muscle strength, poorer lung function and reduced quality of life (35). Reduced physical activity can result in deconditioning, obesity, cardiovascular disease and metabolic syndrome (8). This is of particular concern in children taking long-term 
corticosteroids and in subsets of JDM with lipodystrophy (associated with insulin resistance, diabetes mellitus and hyperlipidaemia).

Using myometry, magnetic resonance imaging (MRI) and measurement of serum creatine kinase $(\mathrm{CK})$ / lactate dehydrogenase (LDH) levels, a study demonstrated that exercise did not increase muscle inflammation in children with JDM (36). Subsequently, a longitudinal study showed 12 weeks of twice-a-week aerobic and resistance training exercise for children with mild chronic JDM improved muscle strength and function, bone density, aerobic conditioning and quality of life (33). A more recent randomised controlled trial demonstrated that a 12 week home exercise programme was safe and led to significant improvement in long jump distance, number of push ups and parental child health assessment questionnaire score, but statistical significance was not achieved between the two groups for maximal oxygen uptake, isometric muscle strength and fatigue; possibly because patients were on average leading active lifestyles with high baseline levels (37). Beyond childhood, 12 weeks of moderate intensity aerobic training for adolescents and adults in remission has been found to increase cardiovascular fitness and oxidative capacity (37).

\section{[B] Psychological interventions}

Children with JDM, siblings and parents are vulnerable to psychological distress and could benefit from psychosocial assessments and interventions at disease onset and throughout the illness course (38). In a recent study, parents of children with JDM reported difficulties in family communication and functioning, and increased conflicts and worry (38). It has been shown that children within families with poor family functioning have reduced ability to adjust (39). This highlights the value of focusing psychological assessment and therapy on not only the child but the entire family unit. Corticosteroid use has also been associated with anxiety, low mood, hypomania and psychotic symptoms in susceptible individuals (40). Many paediatric rheumatology services now have dedicated psychologists and social workers. 
Disease activity may impact school attendance, exam performance and disrupt friendships. Without adequate support, this might limit educational and career prospects, impair the ability to form social relationships and damage self-esteem. In one study examining functional outcomes, three of the 65 patients studied reported failing a grade related to missing school due to JDM (41). Subsequently, all 65 children within the cohort achieved well educationally and reported that JDM did not interfere with employment.

\section{[B] Long-term prognosis and management of complications}

The variability of outcome in JDM makes discussions on prognosis challenging $(1,41,42)$. Furthermore, outcomes have evolved significantly due to early aggressive treatment with corticosteroids, DMARDS and biologics. As a result, published long-term outcome data might not accurately reflect the present JDM disease course. Currently identified risk factors for chronic illness include longer duration of untreated disease and higher skin disease activity at diagnosis, persistent Gottron's papules at 3 and 6 months and periungal nailfold capillary changes at 6 months after diagnosis, documented infection within six months of diagnosis, abnormal subcutaneous fat signal on magnetic resonance imaging at diagnosis, initial muscle biopsy showing extensive active myopathic changes, severe arteropathic changes, severe capillary loss and muscle infarcts, and the presence of anti-p155/140 (antiTIF-1) and anti-Ro antibodies (4). In addition a recent study suggests that patients with either anti-TIF-1 or anti-MDA-5 antibodies have a higher chance of still being on disease modifying medication at 5 years (as a surrogate measure of chronicity or disease severity), after diagnosis than those with anti-Mi-2 antibodies (6).

\section{[C] Musculoskeletal and mucocutaneous}

Long-term active muscle disease results in chronic muscle weakness or dysfunction, and has been found in $34 \%$ of patients in a multicenter study across Europe and Latin America (43). Chronic skin disease can lead to long-term damage such as cutaneous scarring or atrophy, seen in $53 \%$ of patients (43). 
Reported prevalence of calcinosis in JDM cohorts is between 10 and 70\% (44), influenced by methods of data collection, length of follow up and changing treatment practices over time. It occurs more often within 5 years post JDM onset but can range from time of onset to many years after diagnosis (45). Predictors include African American race (44), male (46), younger age of disease onset, having TNFalpha-308A or IL-1alpha-889C polymorphisms, anti-NXP2 autoantibodies, delay in treatment, higher initial CK level, prolonged elevation of muscle enzymes, higher disease activity 6 months post diagnosis (46), and longer duration of disease (44). The SHARE consensus-based recommendations advise actively examining for calcinosis by manual palpation, with the use of plain radiographs where necessary (15). A number of treatment options for calcinosis have been explored including immunosuppressants, drugs targeting calcium metabolism, and surgery; however no intervention is reproducibly effective and evidence is limited to small case reports (44). Furthermore, there is no scoring system to grade extent and severity of calcinosis. Development of a tool may be helpful in determining efficacy of drugs and identifying children at greatest risk of complications. Complications of calcinosis include pain, joint contractures, and risk of infection from staphylococcal, streptococcal or mycobacterial organisms if deposits break the skin surface (44). Over time, calcinosis can spontaneously regress (most likely with inactive disease or superficial lesions) or enlarge (44). Consensus guidance recommends a prompt stepwise increase in immunosuppressive medication in the presence of calcinosis, since reports suggest that aggressive therapy may decrease the incidence of calcinosis and aid regression of established lesions $(18,44)$.

Lipodystrophy occurs in $10-30 \%$ of patients $(47,48)$, most commonly five years after diagnosis of JDM (49). Associations include joint contractures, calcinosis, muscle atrophy, chronic continuous illness course and facial erythema (49). Erythroderma and the presence of p155 autoantibody are associated specifically with generalised lipodystrophy. Erythroderma is also associated with partial lipodystrophy, while panniculitis and dysphonia 
are associated with focal lipodystrophy (49). It has been suggested that MRI could be useful in confirming diagnosis of lipodystrophy or monitoring response to treatment (49). Patients with all types of lipodystrophy are at increased risk of hypertriglyceridemia and those with generalised and partial disease have increased risk of insulin resistance and diabetes (49). Complications include steatosis and ovarian enlargement (49). Acanthosis nigricans, hypertrichosis and low leptin levels can be found in patients with generalised disease, while fat redistribution is seen in partial disease (49). The most appropriate treatment of JDMassociated lipodystrophy is not well established. Metabolic abnormalities in patients with various forms of lipodystrophy respond to metabolic therapies such as troglitazone (50), but further research is needed to study the safety and efficacy of metabolic therapies in JDM.

\section{[C] Pulmonary}

Children with JDM may suffer from interstitial lung disease (ILD) and respiratory muscle weakness. Pulmonary involvement is reported early in the disease course and deteriorates at times of high disease activity (51). ILD has been associated with the presence of antiMDA-5 autoantibodies (52) and elevated Krebs von den Lungen 6 levels (produced by type II pneumocytes and respiratory bronchiolar epithelial cells) (53). Typical appearances on high resolution computed tomography (CT) include linear atelectasis, micro-nodules, groundglass attenuation, expiratory trapping, thickening of bronchial walls, bronchiectasis, fibrosis and consolidation (54). Pulmonary function tests can reveal either restrictive and obstructive defects (54). Restrictive lung disease has been associated with a greater long-term damage outcome (51). Respiratory muscle weakness does not appear to correlate with the Childhood Myositis Assessment Scale (routinely assessed in clinic in some cohorts of patients) (54) and by the time children exhibit respiratory symptoms, damage to lung parenchyma could be irreversible. These issues underline the value of identifying children with pulmonary involvement early. 
SHARE recommends all children with JDM should have pulmonary function tests including carbon monoxide diffusion capacity at time of diagnosis with further testing (such as high resolution CT chest) in those with restrictive disease (15). Results of pulmonary function tests can be difficult to interpret in young children (15) due to difficulty in engaging them in the test and limited reference data for this age group. The radiation risk of repeated CT scanning needs to be considered (15). SHARE advise there is insufficient evidence to guide on frequency of tests although clinicians should be aware of risk of lung involvement particularly in children with high myositis damage index scores and those with anti-RNA synthetase antibodies (15).

Children identified with ILD should be treated aggressively with a combination of corticosteroids and immunosuppressant drugs (55). In acute disease with respiratory insufficiency, treatment with cyclophosphamide or IVIG can be effective (23). It is necessary to balance drug complications against deterioration of pulmonary function on an individual basis, and there is ongoing need to investigate if these therapies improve long term pulmonary as well as overall outcomes.

\section{[C] Cardiac}

Systolic and diastolic dysfunction has been observed in JDM and correlates with skin (not muscle) disease activity at one year post JDM onset, and persists even when disease is inactive (56). Long terms studies are needed to investigate clinical implications of pump dysfunction and whether dysfunction is an early marker of systolic and diastolic failure. Children with JDM have increased rates of hypertension and dyslipidaemia (57). There are no studies to date on coronary artery disease in JDM; however it is possible that these metabolic disturbances could accelerate coronary artery atherosclerosis, making young adults with JDM more susceptible to ischaemic heart disease. Children with JDM have increased prevalence of ECG abnormalities and reduced heart rate variability (thought to be 
an indicator of autonomic dysfunction linked to increased rate of cardiac events(58)) (57). Pericarditis and myocarditis have also been reported in a small number of studies (57).

SHARE guidelines recommend ECG and echocardiography for all children with JDM (15). Assessment of long axis strain and E/é (E, early diastolic transmitral flow; é, early diastolic tissue velocity), as markers for systolic and diastolic involvement on echo have been recommended (57). SHARE advise repeated investigations for those with hypertension, high disease activity one year post diagnosis, long-term high corticosteroid burden or chronic ongoing active disease, in addition to long term follow-up for high risk children. There is currently insufficient evidence to recommend on frequency of investigations or length of follow-up. Besides aggressive immunosuppression, there is limited experience on use of cardiac drugs in JDM. Longitudinal follow-up is necessary to understand long term implications of cardiac involvement, and safety and efficacy of treatments.

\section{[C] Gastrointestinal}

Risk of aspiration is greatest around the time of diagnosis or soon after when disease is at its most severe, and does not always correlate with validated muscle weakness scores such as the Childhood Myositis Assessment Scale (CMAS) or Manual Muscle Test (MMT) scores (15). It is crucial that all children presenting with coughing during swallowing or nasal speech have formal assessments (such as speech and language therapy assessment, video fluoroscopy or barium studies) (15), particularly since pharyngeal involvement has been associated with poorer prognosis (59). Nasogastric feeding may be necessary for short periods to time to reduce risk of aspiration. Vasculitis and thromboses of vessels supplying the gastrointestinal tract can lead to malabsorption and intestinal ulceration with perforation in severe cases $(60,61)$. Ulceration and perforation can occur early or late in disease, even when muscle and skin disease activity is mild $(60,62)$. Symptoms may include persistent or severe abdominal pain with vomiting, haematemesis, constipation or bloody stools. In some 
cases abdominal pain can be the only symptom, and long-term corticosteroids can mask abdominal signs, so careful assessment is needed (62). It has been suggested that aggressive biological treatments and timely surgical interventions are important in reducing mortality rate in ulceration and perforation (62).

\section{[C] Endocrine}

Growth failure is a feature of cumulative damage in JDM, and occurs in around $10 \%$ of patients (46). Reduced bone mineral density (BMD) has been identified at diagnosis and during disease course. Predictors include longer duration of untreated disease (63) and lower weight (64). High disease activity, high-dose corticosteroids, reduced mobility during muscle weakness, active avoidance of sunlight, anorexia, gastrointestinal vasculitis impairing absorption of vitamin D and calcium, and ovarian failure associated with disease or cytotoxic therapy are speculated to be associated with low BMD (64), but more studies are necessary to investigate these associations. Peak BMD achieved in early adulthood is a significant determinant of later life osteoporosis, so it is important to consider prophylaxis with vitamin D and calcium (63). Older age of menarche compared to the general population has been recognised in JDM, with higher follicle-stimulating hormone (lower ovarian reserve), lower prolactin and higher progesterone (possible luteal dysfunction) (65). Dysregulation of hormone levels could be associated with disease pathogenesis or treatment with corticosteroids, which can interfere with the hypothalamic-pituitary-ovarian axis. No difference in frequency of menstrual disturbances or development of secondary sexual characteristics have been observed (65).

\section{[C] Mortality}

While overall mortality rate has significantly improved (falling from $30 \%(66)$ to less than $2 \%$ (41)) since introduction of corticosteroids, DMARDS and novel biologics, the systemic inflammatory response is still profound in some children with JDM, and for a small subset, the resulting pulmonary, gastrointestinal or multisystem failure is fatal (67). Risk factors 
include delay to treatment, older age, severe disease activity at onset, and weight loss (67).

This reiterates the importance of close clinical monitoring and escalating

immunosuppressive treatments for children at risk.

\section{[C] Future treatments}

With significant investment into basic science, the enthusiasm and contributions of many children (and parents) with JDM, and collaboration with the pharmaceutical industry, novel targets and new therapies have been identified. Recent evidence suggested dysregulation of interferon (IFN) in JDM (68). Janus Kinase (JAK) acts downstream of IFN, and JAK inhibitors have been used to good effect in children with interferonopathies (some of these children bear clinical features similar to JDM) (8). Use of JAK inhibitors in JDM is being trialed in North America and Europe, and it is thought that children with evidence of chronic endothelial injury may be most suitable for this therapy.

Cytotoxic T cell Lymphocyte Antigen-4 (CTLA-4), CD28 and CD86 are expressed on muscle cells or inflammatory cells within muscles in inflammatory myopathies (8). Abatacept is a CTLA-4 fusion protein that binds to CD80/CD86 present on antigen presenting cells, preventing binding of CD80/CD86 to CD28 on T cells, inhibiting T cell activation. Abatacept in combination with sodium thiosulfate was reported to control muscle and skin disease, stop progression of calcinosis and reduce corticosteroid burden in a child with severe resistant JDM (69). Currently, a trial of abatacept in refractory moderately active JDM is in progress in the United States.

Serum IL-6 has been correlated with disease activity in JDM (68). Case reports of adults with polymyositis and an adult with overlap syndrome identify improvement of skin and muscle disease with tocilizumab (IL-6 receptor antibody) (8). To date, experience of tocilizumab in JDM is very limited. 


\section{[A] Clinical monitoring}

Regular monitoring in JDM is essential; management plans should be tailored to fluctuating disease activity levels, evidence of disease damage, and the evolving psychosocial needs of the developing child. A thorough history and examination, including muscle strength testing and skin examination is necessary at diagnosis and at every encounter. There has been increasing emphasis on frequent observation, early detection and prompt treatment of skin disease even in the absence of muscle pathology (70). In view of its prognostic implications (42), it is useful to review periungal capillary changes at each opportunity. While some studies suggest nailfold capillary density is a marker of both skin and muscle disease activity $(71,72)$, other researchers show end row capillary loss to correlate solely with skin disease (70).

At diagnosis, full blood count, erythrocyte sedimentation rate, urea and electrolytes, liver function tests, muscle enzymes, and autoantibodies are recommended (15). Serum muscle enzymes can be indicators of disease activity, but often are normal, particularly later in disease course (47). It is valuable to measure CK, LDH, alanine aminotransferase (ALT), aspartate aminotransferase (AST), and, where available, adolase to maximise the chance of finding at least one elevated enzyme. A number of sensitive disease activity biomarkers in the peripheral blood are currently under investigation, including type I IFN gene and chemokine levels, galectin, and IL-6, IL-8 and TNF levels (73).

Radiological investigations are helpful in determining extent of muscle disease and major organ involvement. MRI (T2 weighted protocols), when reported by experienced radiologists, may be useful in helping to monitor disease activity (74). A recently developed MRI scoring tool designed for defining muscle inflammation was shown to be accurate for the single 
reader, but variable between individuals, so requires further validation before this can be incorporated into clinical practice (74).

Clinical and research tools are available to help quantify muscle and skin disease, major organ involvement, functional ability and quality of life. These standardised assessments of disease activity (reversible aspects related to active inflammation) and damage (irreversible scarring from repeated inflammation or secondary to treatment) are useful for monitoring disease over time. They can help guide decisions on treatment escalation or reduction, and streamline data collection to facilitate collaboration and meta-analyses (75). Many of these tools were initially designed for research purposes within Paediatric Rheumatology International Trials Organisation (PRINTO) (76) and International Myositis Assessment and Clinical Studies Group (IMACS) (76) core sets (Table 5), but now are increasingly being incorporated into clinical practice. Recently, IMACS and PRINTO have engaged in a joint effort to develop validated response criteria for JDM, including criteria for minimal, moderate and major clinical response, allowing either IMACS or PRINTO core set measures to be used, thus resolving the differences between IMACS and PRINTO core sets (76).

\section{[B] Disease activity tools \\ [C] Clinician-completed}

\section{[D] Muscle}

CMAS and MMT are validated examination tools for assessing muscle disease. CMAS uses 14 maneuvers to measure strength, function and endurance (77). As for many assessments in children, thresholds for active disease may need to be adjusted according to the child's age, as it has been shown that healthy children up to 9 years may not always achieve the maximum CMAS score $(78,79)$. Total MMT is an extensive assessment of 26 bilateral muscle groups. Recently, this has been condensed to MMT8 (measurement of 8 axial, proximal and distal muscles unilaterally that correlates well with total MMT) for practical use 
within the busy clinical environment (80). CMAS and MMT share many similarities, and there is potential to investigate for redundancy between these tools and to validate a combined shortened tool for clinical practice.

\section{[D] Skin}

Many tools have been used to assess extent of skin involvement, although it is yet to be determined which tool is most accurate and reliable in JDM. The Cutaneous Assessment Tool (CAT) measures the full range of skin activity and damage, and has been partially validated in a large JDM cohort demonstrating good reliability (81). An abbreviated CAT performs similarly to the full CAT, and is favoured in clinical practice (81). A recent study comparing the CAT, skin DAS and MITAX tools for assessing skin in JDM suggested a new tool may be required which incorporates all aspects of skin disease (82). The modified Cutaneous Dermatomyositis Disease Area and Severity Index (CDASI - Version 2) evaluates 3 disease activity measures (erythema, scale, erosion/ulceration) and 2 damage features (poikiloderma, calcinosis) as well as activity and /or damage due to Gottron's patches, periungal changes and alopecia. A recent study compared the CDASI and CAT in JDM $(n=14)$ and found both tools to be reliable when used by paediatric dermatologists or rheumatologists (83).

\section{[D] Global}

The Myositis Disease Activity Assessment Tool (MDAAT) integrates the Myositis Disease Activity Assessment Visual Analogue Scale (MYOACT) and Myositis Intention to Treat Activities Index (MITAX). It appraises in detail disease activity in muscle, skin, and several extra-muscular/extra-cutaneous systems (skeletal, gastrointestinal, pulmonary, cardiac and constitutional), and has been shown to have good validity and reliability (77). The Disease Activity Score (DAS) assesses overall muscle and skin disease activity; reported as separate or combined muscle and skin scores (where there is approximately equal weighting between 
the two systems). DAS is thought to sensitively detect clinically important changes in disease activity over time, although the sensitivity and specificity may diminish in children with the most severe damage (77). Physician Visual Analogue Scale (VAS) is a global judgement based on all the information available at the time of evaluation including history, examination, blood results, and prescribed medications. It has good validity and reliability and responsiveness in longitudinal monitoring (77).

\section{[C] Patient-completed \\ [D] Global}

Patient/parent VAS is a global judgement made by the older child or parent based on disease activity in muscle, skin and major organs. Notably, physician VAS and patient VAS are not collinear (84), reflecting the contrasting emphasis placed by clinician and patient on different facets of a very multidimensional disease. The Childhood Assessment Questionnaire (CHAQ) is a quick and simple instrument that measures overall wellbeing, physical function, pain intensity and disability. It has good reliability and validity and responsiveness; therefore suitable for longitudinal monitoring (77). However, this tool has floor (scores cluster near zero in mild disease) and ceiling effects (does not distinguish between activity and damage resulting in poor sensitivity and specificity for children with most severe damage) $(77,85)$.

\section{[D] Quality of life}

A large number of quality of life tools are available, and in recent years, instruments specifically tailored to the needs of children with JDM are emerging. The Child Health Questionnaire $(\mathrm{CHQ})$ is a widely used set of questions, validated for use in JDM, assessing physical and psychological wellbeing, ability to participate in activities of daily living, and psychosocial effects on the family (77). The Juvenile Dermatomyositis Multidimensional Assessment Report (JDMAR) is JDM-specific tool currently undergoing further validation. Its aims to assess function, quality of life, fatigue and treatment adverse effects (86). 


\section{[B] Disease damage tools}

The Myositis Damage Index (MDI) is a clinician-based assessment that has been partially validated in JDM (77). It is a useful measure of global damage secondary to chronic inflammation and drug toxicity. It scores the severity of long-term damage in different organ systems including muscle, skin, gastrointestinal, pulmonary, cardiac, peripheral vascular and endocrine systems, eyes, as well as occurrence of infection and malignancy. This tool has been useful in facilitating understanding of long-term outcomes of JDM, and has highlighted that a considerable number of adolescents and adults with JDM suffer from moderate to severe damage as a result of chronic inflammation $(1,43,46)$.

\section{[B] Remission criteria}

PRINTO have established data-driven criteria for clinically inactive disease (CID) to guide clinical practice and research (87). Patients are classified as having CID if they obtain at least 3 out of 4 variables of $C P K \leq 150, C M A S \geq 48, M M T \geq 78$, and physician global assessment $(P G A) \leq 0.2$. However, since 3 of these variables are muscle specific, this score may underestimate skin involvement. It has been suggested that PGA should be an essential criterion when defining CID to avoid this (88).

\section{[B] Registries and common datasets}

Through a robust consensus process, an internationally agreed dataset for JDM has been defined, along with an accompanying glossary of definitions, for use in clinical practice (89). The aim is for this to be incorporated into existing national and international research registries to allow comparison of data between groups. The development of registries is a smart strategy to build statistical power, maximise yield from precious patient data and samples, save on overall research costs, increasing efficiency and accelerating acquisition of knowledge in a rare and heterogeneous disease $(90,91)$. Registries aid identification of patients for interventional trials, are an important resource in epidemiological research, help 
estimation of disease burden, determination of long-term comorbidities including rare events, and provide quality assurance in safety of medications. When linked to biobanks, they facilitate identification of prognostic markers of disease and understanding of subphenotypes $(90,91)$. Registries could also be beneficial in clinical practice; those that are easily accessible and have user-friendly interfaces are valuable aid memoirs for assessing patients in clinic, particularly for trainees less familiar with JDM.

The Juvenile Dermatomyositis Cohort and Biomarker Study and Repository (UK and Ireland) has facilitated research by collecting prospective clinical data linked to serial biological sampling (92). Projects led by group members and outside investigators have included work on genetics, autoantibodies, muscle biopsy pathology, imaging studies, exercise, and therapeutic targets in JDM. CARRA has developed a multicentre registry in the United States and Canada for paediatric rheumatic diseases and is in the final stages of including JDM (https://carragroup.org/). Euromyositis is web-based registry and biobank for adults and children with inflammatory myopathies in Europe that also welcomes applications internationally (93).

\section{[B] Statistical models}

As registry databases are collating growing numbers of observations and variables, paediatric rheumatologists are encountering new challenges in data cleaning, preparation and analysis, but also finding opportunities to explore novel research methods. A recent study explored the possibility of modelling longitudinal outcomes in JDM (94). Using data from almost 3000 clinic visits, clinical markers and symptoms were used as covariates in a regression model to predict disease activity outcomes. In the future, with bigger datasets and increasingly reliable models, statistical models may play a revolutionary role in stratifying children for personalised medicine and maximising research efficiency through discerning the most relevant outcome markers for research studies (94). 


\section{[A] Summary}

Advances in genetics, immunology and histology are accelerating understanding of JDM pathogenesis, influencing management, and improving prognosis. MSAs and muscle biopsies are now routinely taken in specialist centres and used alongside standard assessments to guide treatment. Further research is needed to develop tools (combining genotype, autoantibody status and muscle histology) to predict drug response and long-term complications. Understanding aberrant immune pathways has facilitated the introduction of several biologics off-label, which have significantly improved outcomes for some children. Where expectations are evolving towards sustained clinical disease inactivity for every child, ongoing studies are necessary to identify novel targets for children with recalcitrant disease, and to compare safety and efficacy of drugs. In this rare and heterogeneous disease, national and international collaborations and registries (with linked biobanks) have been pivotal in driving research progress that was previously hampered by low statistical power. Over recent years, multicentre collaborations have defined genetic/serotypic disease subtypes, exposed new therapeutic targets, explored novel imaging techniques, and determined the role of exercise in the management of JDM. A new challenge researchers face is how to exploit the full potential of increasingly large volumes of data accumulating in registries. There is mounting interest in integrating clinical practice and research to maximise efficiency. Recently, an internationally agreed dataset for JDM for use in clinical practice was defined, with the aim to facilitate data comparison if incorporated into registries. While impressive advances have been achieved, subsets of children continue to experience active disease into adulthood. There is an ongoing duty to foster international collaborations to maximise basic science, translational and clinical research to ensure the best outcome for every future child. 


\section{[A] Practice Points}

- Early aggressive treatment with stepwise use of a combination of corticosteroids, disease modifying anti-rheumatic drugs and biologics could achieve early remission and reduce risk of complications from disease and long-term drug toxicity

- Frequent observation, early detection and prompt treatment of skin disease even in the absence of muscle pathology has prognostic importance

- Using consensus treatment plans during daily clinical practice could limit treatment practice variation to facilitate development of comparative effectiveness studies

- Exercise programmes are safe and could improve muscle strength and function, aerobic conditioning and quality of life in children with JDM

- Children with JDM, their siblings and parents could benefit from psychosocial assessments and interventions at disease onset and throughout illness course

- Disease activity and damage tools standardise assessment of muscle and skin disease, major organ involvement, functional ability and quality of life, and are helpful in guiding decisions on treatment

\section{[A] Research Agenda}

- Genotype, autoantibody status, muscle histology score and early clinical features should be important biomarkers to predict disease prognosis and guide personalised treatment

- Reliable, sensitive and easy to measure biomarkers are needed to monitor disease activity. Peripheral blood levels of Type I IFN gene and chemokine levels, galectin, IL-6, IL-8 and TNF are potential candidates

- Further research is necessary to find novel biological targets for children with recalcitrant disease, and to compare safety and efficacy of biological agents. JAK 
inhibitors and Abatacept are being trialled in JDM and could be beneficial for certain genetic/serotypic subsets of patients

- Registries should not only be useful in building statistical power for research but also facilitate daily clinical practice such as acting as aid memoirs for assessing patients

- Incorporation of the newly defined internationally agreed dataset for JDM into clinical practice and existing registries will facilitate comparison and merging of data between groups

- With larger datasets, modelling of longitudinal outcomes, stratification of children for personalised medicine and defining most relevant outcome markers for research may be possible 


\section{Figure legends:}

Fig 1. Evidence for mechanisms contributing to juvenile dermatomyositis pathogenesis. (3, $4,8)$

[Footnote - Figure 1]: $p D C$ : plasmacytoid dendritic cell; c': complement; Treg: regulatory T cell; IL: interleukin; $M C P$ : monocyte chemoattractant protein; IFN: interferon; MHC: major histocompatibility complex; CXCL: Chemokine (C-X-C motif) ligand; MRP: myeloid-related protein; TLR: toll-like receptor; MAC: membrane attack complex; ICAM: intercellular adhesion molecule; VCAM: vascular cell adhesion molecule

Fig 2. Flow chart adapted from Single Hub and Access point for Paediatric Rheumatology in Europe (SHARE) recommendations for treatment of juvenile dermatomyositis. Adapted from (15)

[Footnote - Figure 2]: IV: intravenous; PO: oral; MTX: methotrexate; IVIG: intravenous immunoglobulin; DMARD: disease modifying anti-rheumatic drug; MMF: mycophenolate mofetil

Fig 3. Flow chart adapted from Children's Arthritis and Rheumatology Research Alliance (CARRA) Consensus Treatment Plans (CTPs) for treatment of moderately severe juvenile dermatomyositis. Adapted from $(16,17)$

[Footnote - figure 3]: MP: methylprednisolone; IV: intravenous; MTX: methotrexate; SC: subcutaneous; PO: oral; IVIG: intravenous immunoglobulin; MRI: magnetic resonance imaging; EMG: electromyography; PGA: physician global assessment; CMAS: Childhood Myositis Assessment Scale; MMT; manual muscle testing; Gl: gastrointestinal; ICU: intensive care unit; CNS: central nervous system; MMF: mycophenolate mofetil; AZA: azathioprine. 


\section{[A] Acknowledgements}

The authors would like to thank the families and patients who have generously agreed to be part of the UK JDM Cohort and Biomarker study

(http://www.juveniledermatomyositis.org.uk), and all the contributors to the UK Juvenile dermatomyositis Research Group. 


\section{[A] References}

1. Mathiesen P, Hegaard H, Herlin T, Zak M, Pedersen FK, Nielsen S. Longterm outcome in patients with juvenile dermatomyositis: a cross-sectional follow-up study. Scand J Rheumatol. 2012 Feb;41(1):50-8. PubMed PMID: 22044089. Epub 2011/11/01. eng.

2. Miller FW, Cooper RG, Vencovský J, Rider LG, Danko K, Wedderburn LR, et al. Genome-wide association study of dermatomyositis reveals genetic overlap with other autoimmune disorders. Arthritis Rheum. 2013 Dec;65(12):3239-47. PubMed PMID: 23983088. PMCID: PMC3934004. eng.

3. Wedderburn LR, Rider LG. Juvenile dermatomyositis: new developments in pathogenesis, assessment and treatment. Best Pract Res Clin Rheumatol. 2009 Oct;23(5):665-78. PubMed PMID: 19853831. PMCID: PMC2774891. eng.

4. Rider LG, Nistala K. The juvenile idiopathic inflammatory myopathies: pathogenesis, clinical and autoantibody phenotypes, and outcomes. J Intern Med. 2016 Jul;280(1):24-38. PubMed PMID: 27028907. PMCID: PMC4914449. Epub 2016/03/30. eng.

5. Tansley SL, Simou S, Shaddick G, Betteridge ZE, Almeida B, Gunawardena $\mathrm{H}$, et al. Autoantibodies in juvenile-onset myositis: Their diagnostic value and associated clinical phenotype in a large UK cohort. J Autoimmun. 2017;Nov(84):5564. PubMed PMID: 28663002. Epub 2017/06/26. eng.

6. Deakin CT, Yasin SA, Simou S, Arnold KA, Tansley SL, Betteridge ZE, et al. Muscle Biopsy Findings in Combination With Myositis-Specific Autoantibodies Aid Prediction of Outcomes in Juvenile Dermatomyositis. Arthritis Rheumatol. 2016 Nov;68(11):2806-16. PubMed PMID: 27214289. PMCID: PMC5091622. Epub 2016/10/09. eng. 
7. Rider LG, Shah M, Mamyrova G, Huber AM, Rice MM, Targoff IN, et al. The myositis autoantibody phenotypes of the juvenile idiopathic inflammatory myopathies. Medicine (Baltimore). 2013 Jul;92(4):223-43. PubMed PMID: 23877355. PMCID: PMC3721421. eng.

8. Papadopoulou C, Wedderburn LR. Treatment of Juvenile Dermatomyositis: An Update. Paediatr Drugs. 2017 May. PubMed PMID: 28550457. Epub 2017/05/26. eng.

9. Varsani H, Charman SC, Li CK, Marie SK, Amato AA, Banwell B, et al. Validation of a score tool for measurement of histological severity in juvenile dermatomyositis and association with clinical severity of disease. Ann Rheum Dis. 2015 Jan;74(1):204-10. PubMed PMID: 24064003. PMCID: PMC4283618. Epub 2013/09/24. eng.

10. López De Padilla CM, Vallejo AN, Lacomis D, McNallan K, Reed AM. Extranodal lymphoid microstructures in inflamed muscle and disease severity of new-onset juvenile dermatomyositis. Arthritis Rheum. 2009 Apr;60(4):1160-72. PubMed PMID: 19333937. eng.

11. Miles L, Bove KE, Lovell D, Wargula JC, Bukulmez H, Shao M, et al. Predictability of the clinical course of juvenile dermatomyositis based on initial muscle biopsy: a retrospective study of 72 patients. Arthritis Rheum. 2007 Oct;57(7):1183-91. PubMed PMID: 17907236. eng.

12. Manlhiot C, Liang L, Tran D, Bitnun A, Tyrrell PN, Feldman BM. Assessment of an infectious disease history preceding juvenile dermatomyositis symptom onset. Rheumatology (Oxford). 2008 Apr;47(4):526-9. PubMed PMID: 18304939. Epub 2008/02/27. eng. 
13. Habers GE, Huber AM, Mamyrova G, Targoff IN, O'Hanlon TP, Adams S, et al. Brief Report: Association of Myositis Autoantibodies, Clinical Features, and Environmental Exposures at Illness Onset With Disease Course in Juvenile Myositis. Arthritis Rheumatol. 2016 Mar;68(3):761-8. PubMed PMID: 26474155. PMCID: PMC4767657. eng.

14. Tezak Z, Hoffman EP, Lutz JL, Fedczyna TO, Stephan D, Bremer EG, et al. Gene expression profiling in DQA $1{ }^{*} 0501+$ children with untreated dermatomyositis: a novel model of pathogenesis. J Immunol. 2002 Apr;168(8):4154-63. PubMed PMID: 11937576. eng.

15. Enders FB, Bader-Meunier B, Baildam E, Constantin T, Dolezalova P, Feldman BM, et al. Consensus-based recommendations for the management of juvenile dermatomyositis. Ann Rheum Dis. 2017 Feb;76(2):329-40. PubMed PMID: 27515057. PMCID: PMC5284351. Epub 2016/08/11. eng.

16. Huber AM, Giannini EH, Bowyer SL, Kim S, Lang B, Lindsley CB, et al. Protocols for the initial treatment of moderately severe juvenile dermatomyositis: results of a Children's Arthritis and Rheumatology Research Alliance Consensus Conference. Arthritis Care Res (Hoboken). 2010 Feb;62(2):219-25. PubMed PMID: 20191521. PMCID: PMC2909837. eng.

17. Huber AM, Robinson AB, Reed AM, Abramson L, Bout-Tabaku S, Carrasco R, et al. Consensus treatments for moderate juvenile dermatomyositis: beyond the first two months. Results of the second Childhood Arthritis and Rheumatology Research Alliance consensus conference. Arthritis Care Res (Hoboken). 2012 Apr;64(4):546-53. PubMed PMID: 22076847. PMCID: PMC3315594. eng. 
18. Huber AM, Kim S, Reed AM, Carrasco R, Feldman BM, Hong SD, et al. Childhood Arthritis and Rheumatology Research Alliance Consensus Clinical Treatment Plans for Juvenile Dermatomyositis with Persistent Skin Rash. J Rheumatol. 2017 Jan;44(1):110-6. PubMed PMID: 27803135. Epub 2016/11/01. eng.

19. Kim S, Kahn P, Robinson AB, Lang B, Shulman A, Oberle EJ, et al. Childhood Arthritis and Rheumatology Research Alliance consensus clinical treatment plans for juvenile dermatomyositis with skin predominant disease. Pediatr Rheumatol Online J. 2017 Jan;15(1):1. PubMed PMID: 28077146. PMCID: PMC5225591. Epub 2017/01/11. eng.

20. Spencer CH, Rouster-Stevens K, Gewanter H, Syverson G, Modica R, Schmidt K, et al. Biologic therapies for refractory juvenile dermatomyositis: five years of experience of the Childhood Arthritis and Rheumatology Research Alliance in North America. Pediatr Rheumatol Online J. 2017 Jun;15(1):50. PubMed PMID: 28610606. PMCID: PMC5470177. Epub 2017/06/13. eng.

21. Stringer E, Bohnsack J, Bowyer SL, Griffin TA, Huber AM, Lang B, et al. Treatment approaches to juvenile dermatomyositis (JDM) across North America: The Childhood Arthritis and Rheumatology Research Alliance (CARRA) JDM Treatment Survey. J Rheumatol. 2010 Sep;37(9):1953-61. PubMed PMID: 20595275. Epub 2010/07/01. eng.

22. Deakin C, Campanilho-Marques R, Simou S, Moraitis E, Pullenayegum E, Wedderburn L, et al. Analysis of Efficacy and Safety of Cyclophosphamide in Juvenile Dermatomyositis Using a Large National UK Cohort [abstract]. Arthritis Rheumatol 2016;68 (suppl 10). 
23. Martin N, Wedderburn L, Davidson J, Beard L, Pilkington C. Comparison of data from the juvenile dermatomyositis national (UK \& Ireland) cohort biomarker study and repository for idiopathic inflammatory myopathies with a survey of current practice throughout the UK and Ireland [abstract]. Pediatric Rheumatology Online Journal; 2011. p. 57.

24. Guseinova D, Consolaro A, Trail L, Ferrari C, Pistorio A, Ruperto N, et al. Comparison of clinical features and drug therapies among European and Latin American patients with juvenile dermatomyositis. Clin Exp Rheumatol. 2011 JanFeb;29(1):117-24. PubMed PMID: 21345298. Epub 2011/02/23. eng.

25. Ruperto N, Pistorio A, Oliveira S, Zulian F, Cuttica R, Ravelli A, et al. Prednisone versus prednisone plus ciclosporin versus prednisone plus methotrexate in new-onset juvenile dermatomyositis: a randomised trial. Lancet. 2016 Feb;387(10019):671-8. PubMed PMID: 26645190. Epub 2015/11/30. eng.

26. Kim S, El-Hallak M, Dedeoglu F, Zurakowski D, Fuhlbrigge RC, Sundel RP. Complete and sustained remission of juvenile dermatomyositis resulting from aggressive treatment. Arthritis Rheum. 2009 Jun;60(6):1825-30. PubMed PMID: 19479872. PMCID: PMC4254704. eng.

27. Oddis CV, Reed AM, Aggarwal R, Rider LG, Ascherman DP, Levesque MC, et al. Rituximab in the treatment of refractory adult and juvenile dermatomyositis and adult polymyositis: a randomized, placebo-phase trial. Arthritis Rheum. 2013 Feb;65(2):314-24. PubMed PMID: 23124935. PMCID: PMC3558563. eng.

28. Aggarwal R, Loganathan P, Koontz D, Qi Z, Reed AM, Oddis CV. Cutaneous improvement in refractory adult and juvenile dermatomyositis after treatment with 
rituximab. Rheumatology (Oxford). 2017 Feb;56(2):247-54. PubMed PMID: 27837048. Epub 2016/11/11. eng.

29. Campanilho-Marques R, Deakin C, Simou S, Wedderburn L, Pilkington C. Efficacy and Safety of Tumour Necrosis Factor Antagonists in a Large Cohort of Juvenile Dermatomyositis Patients [abstract]. Arthritis Rheumatol. 2016. ;68 (suppl 10). .

30. Riley P, McCann LJ, Maillard SM, Woo P, Murray KJ, Pilkington CA. Effectiveness of infliximab in the treatment of refractory juvenile dermatomyositis with calcinosis. Rheumatology (Oxford). 2008 Jun;47(6):877-80. PubMed PMID: 18403404. Epub 2008/04/09. eng.

31. Rouster-Stevens KA, Ferguson L, Morgan G, Huang CC, Pachman LM. Pilot study of etanercept in patients with refractory juvenile dermatomyositis. Arthritis Care Res (Hoboken). 2014 May;66(5):783-7. PubMed PMID: 24127327. eng.

32. Soybilgic A, Tesher M, Wagner-Weiner L, Onel KB. A survey of steroidrelated osteoporosis diagnosis, prevention and treatment practices of pediatric rheumatologists in North America. Pediatr Rheumatol Online J. 2014;12:24. PubMed PMID: 25053923. PMCID: PMC4105759. Epub 2014/07/09. eng.

33. Omori CH, Silva CA, Sallum AM, Rodrigues Pereira RM, Lúciade Sá Pinto A, Roschel H, et al. Exercise training in juvenile dermatomyositis. Arthritis Care Res (Hoboken). 2012 Aug;64(8):1186-94. PubMed PMID: 22505288. eng.

34. Habers GE, De Knikker R, Van Brussel M, Hulzebos E, Stegeman DF, Van Royen A, et al. Near-infrared spectroscopy during exercise and recovery in children with juvenile dermatomyositis. Muscle Nerve. 2013 Jan;47(1):108-15. PubMed PMID: 23042630. Epub 2012/10/05. eng. 
35. Berntsen KS, Tollisen A, Schwartz T, Kirkhus E, Aaløkken TM, Lund MB, et al. Submaximal Exercise Capacity in Juvenile Dermatomyositis after Longterm Disease: The Contribution of Muscle, Lung, and Heart Involvement. J Rheumatol. 2017 Jun;44(6):827-34. PubMed PMID: 28365577. Epub 2017/04/01. eng.

36. Maillard SM, Jones R, Owens CM, Pilkington C, Woo PM, Wedderburn LR, et al. Quantitative assessments of the effects of a single exercise session on muscles in juvenile dermatomyositis. Arthritis Rheum. 2005 Aug;53(4):558-64. PubMed PMID: 16082634. eng.

37. Habers GE, Bos GJ, van Royen-Kerkhof A, Lelieveld OT, Armbrust W, Takken $\mathrm{T}$, et al. Muscles in motion: a randomized controlled trial on the feasibility, safety and efficacy of an exercise training programme in children and adolescents with juvenile dermatomyositis. Rheumatology (Oxford). 2016 Jul;55(7):1251-62. PubMed PMID: 27018060. Epub 2016/03/27. eng.

38. Kountz-Edwards S, Aoki C, Gannon C, Gomez R, Cordova M, Packman W. The family impact of caring for a child with juvenile dermatomyositis. Chronic IIIn. 2017 Jan:1742395317690034. PubMed PMID: 28133992. Epub 2017/01/01. eng. 39. Pless IB, Roghmann K, Haggerty RJ. Chronic illness, family functioning, and psychological adjustment: a model for the allocation of preventive mental health services. Int J Epidemiol. 1972;1(3):271-7. PubMed PMID: 4669204. eng.

40. Stuart FA, Segal TY, Keady S. Adverse psychological effects of corticosteroids in children and adolescents. Arch Dis Child. 2005 May;90(5):500-6. PubMed PMID: 15851433. PMCID: PMC1720409. eng.

41. Huber AM, Lang B, LeBlanc CM, Birdi N, Bolaria RK, Malleson P, et al. Medium- and long-term functional outcomes in a multicenter cohort of children with 
juvenile dermatomyositis. Arthritis Rheum. 2000 Mar;43(3):541-9. PubMed PMID: 10728746. eng.

42. Stringer E, Singh-Grewal D, Feldman BM. Predicting the course of juvenile dermatomyositis: significance of early clinical and laboratory features. Arthritis Rheum. 2008 Nov;58(11):3585-92. PubMed PMID: 18975314. eng.

43. Ravelli A, Trail L, Ferrari C, Ruperto N, Pistorio A, Pilkington C, et al. Longterm outcome and prognostic factors of juvenile dermatomyositis: a multinational, multicenter study of 490 patients. Arthritis Care Res (Hoboken). 2010 Jan;62(1):6372. PubMed PMID: 20191492. eng.

44. Hoeltzel MF, Oberle EJ, Robinson AB, Agarwal A, Rider LG. The presentation, assessment, pathogenesis, and treatment of calcinosis in juvenile dermatomyositis. Curr Rheumatol Rep. 2014 Dec;16(12):467. PubMed PMID: 25366934. PMCID: PMC5118224. eng.

45. Sato JO, Sallum AM, Ferriani VP, Marini R, Sacchetti SB, Okuda EM, et al. A Brazilian registry of juvenile dermatomyositis: onset features and classification of 189 cases. Clin Exp Rheumatol. 20092009 Nov-Dec;27(6):1031-8. PubMed PMID: 20149327. eng.

46. Sanner H, Gran JT, Sjaastad I, Flatø B. Cumulative organ damage and prognostic factors in juvenile dermatomyositis: a cross-sectional study median 16.8 years after symptom onset. Rheumatology (Oxford). 2009 Dec;48(12):1541-7. PubMed PMID: 19776224. Epub 2009/09/23. eng.

47. McCann LJ, Juggins AD, Maillard SM, Wedderburn LR, Davidson JE, Murray KJ, et al. The Juvenile Dermatomyositis National Registry and Repository (UK and Ireland)--clinical characteristics of children recruited within the first $5 \mathrm{yr}$. 
Rheumatology (Oxford). 2006 Oct;45(10):1255-60. PubMed PMID: 16567354. Epub 2006/03/27. eng.

48. Singh S, Bansal A. Twelve years experience of juvenile dermatomyositis in North India. Rheumatol Int. 2006 Apr;26(6):510-5. PubMed PMID: 16163542. Epub 2005/09/15. eng.

49. Bingham A, Mamyrova G, Rother KI, Oral E, Cochran E, Premkumar A, et al. Predictors of acquired lipodystrophy in juvenile-onset dermatomyositis and a gradient of severity. Medicine (Baltimore). 2008 Mar;87(2):70-86. PubMed PMID: 18344805. PMCID: PMC2674585. eng.

50. Arioglu E, Duncan-Morin J, Sebring N, Rother KI, Gottlieb N, Lieberman J, et al. Efficacy and safety of troglitazone in the treatment of lipodystrophy syndromes. Ann Intern Med. 2000 Aug;133(4):263-74. PubMed PMID: 10929166. eng. 51. Mathiesen PR, Buchvald F, Nielsen KG, Herlin T, Friis T, Nielsen S. Pulmonary function and autoantibodies in a long-term follow-up of juvenile dermatomyositis patients. Rheumatology (Oxford). 2014 Apr;53(4):644-9. PubMed PMID: 24310298. Epub 2013/12/05. eng.

52. Tansley SL, Betteridge ZE, Gunawardena H, Jacques TS, Owens CM, Pilkington $\mathrm{C}$, et al. Anti-MDA5 autoantibodies in juvenile dermatomyositis identify a distinct clinical phenotype: a prospective cohort study. Arthritis Res Ther. 2014 Jul;16(4):R138. PubMed PMID: 24989778. PMCID: PMC4227127. Epub 2014/07/02. eng.

53. Morinishi Y, Oh-Ishi T, Kabuki T, Joh K. Juvenile dermatomyositis: clinical characteristics and the relatively high risk of interstitial lung disease. Mod Rheumatol. 2007;17(5):413-7. PubMed PMID: 17929135. Epub 2007/10/19. eng. 
54. Pouessel G, Deschildre A, Le Bourgeois M, Cuisset JM, Catteau B, Karila C, et al. The lung is involved in juvenile dermatomyositis. Pediatr Pulmonol. 2013 Oct;48(10):1016-25. PubMed PMID: 23281200. Epub 2012/12/31. eng.

55. Tillie-Leblond I, Wislez M, Valeyre D, Crestani B, Rabbat A, Israel-Biet D, et al. Interstitial lung disease and anti-Jo-1 antibodies: difference between acute and gradual onset. Thorax. 2008 Jan;63(1):53-9. PubMed PMID: 17557770. Epub 2007/06/08. eng.

56. Schwartz T, Sanner H, Gjesdal O, Flatø B, Sjaastad I. In juvenile dermatomyositis, cardiac systolic dysfunction is present after long-term follow-up and is predicted by sustained early skin activity. Ann Rheum Dis. 2014 Oct;73(10):180510. PubMed PMID: 23881732. Epub 2013/07/23. eng.

57. Schwartz T, Diederichsen LP, Lundberg IE, Sjaastad I, Sanner H. Cardiac involvement in adult and juvenile idiopathic inflammatory myopathies. RMD Open. 2016;2(2):e000291. PubMed PMID: 27752355. PMCID: PMC5051430. Epub 2016/09/27. eng.

58. Xhyheri B, Manfrini O, Mazzolini M, Pizzi C, Bugiardini R. Heart rate variability today. Prog Cardiovasc Dis. 20122012 Nov-Dec;55(3):321-31. PubMed PMID: 23217437. eng.

59. Taieb A, Guichard C, Salamon R, Maleville J. Prognosis in juvenile dermatopolymyositis: a cooperative retrospective study of 70 cases. Pediatr Dermatol. 1985 Jul;2(4):275-81. PubMed PMID: 4011505. eng. 60. Takeda T, Fujisaku A, Jodo S, Koike T, Ishizu A. Fatal vascular occlusion in juvenile dermatomyositis. Ann Rheum Dis. 1998 Mar;57(3):172-3. PubMed PMID: 9640135. PMCID: PMC1752547. eng. 
61. Magill HL, Hixson SD, Whitington G, Igarashi M, Hannissian A. Duodenal perforation in childhood dermatomyositis. Pediatr Radiol. 1984;14(1):28-30. PubMed PMID: 6694857. eng.

62. Mamyrova G, Kleiner DE, James-Newton L, Shaham B, Miller FW, Rider LG. Late-onset gastrointestinal pain in juvenile dermatomyositis as a manifestation of ischemic ulceration from chronic endarteropathy. Arthritis Rheum. 2007 Jun;57(5):881-4. PubMed PMID: 17530691. PMCID: PMC2099313. eng.

63. Rouster-Stevens KA, Langman CB, Price HE, Seshadri R, Shore RM, Abbott $\mathrm{K}$, et al. RANKL:osteoprotegerin ratio and bone mineral density in children with untreated juvenile dermatomyositis. Arthritis Rheum. 2007 Mar;56(3):977-83. PubMed PMID: 17328075. eng.

64. Castro TC, Terreri MT, Szejnfeld VL, Len C, Fonseca AS, Hilário MO. Bone mineral density of Brazilian girls with juvenile dermatomyositis. Braz J Med Biol Res. 2005 Feb;38(2):309-13. PubMed PMID: 15785843. Epub 2005/02/15. eng.

65. Aikawa NE, Sallum AM, Leal MM, Bonfá E, Pereira RM, Silva CA. Menstrual and hormonal alterations in juvenile dermatomyositis. Clin Exp Rheumatol. 2010 2010 Jul-Aug;28(4):571-5. PubMed PMID: 20598224. Epub 2010/08/31. eng.

66. BITNUM S, DAESCHNER CW, TRAVIS LB, DODGE WF, HOPPS HC. DERMATOMYOSITIS. J Pediatr. 1964 Jan;64:101-31. PubMed PMID: 14100086. eng.

67. Huber AM, Mamyrova G, Lachenbruch PA, Lee JA, Katz JD, Targoff IN, et al. Early illness features associated with mortality in the juvenile idiopathic inflammatory myopathies. Arthritis Care Res (Hoboken). 2014 May;66(5):732-40. PubMed PMID: 24151254. PMCID: PMC4646219. eng. 
68. Bilgic H, Ytterberg SR, Amin S, McNallan KT, Wilson JC, Koeuth T, et al. Interleukin-6 and type I interferon-regulated genes and chemokines mark disease activity in dermatomyositis. Arthritis Rheum. 2009 Nov;60(11):3436-46. PubMed PMID: 19877033. eng.

69. Arabshahi B, Silverman RA, Jones OY, Rider LG. Abatacept and sodium thiosulfate for treatment of recalcitrant juvenile dermatomyositis complicated by ulceration and calcinosis. J Pediatr. 2012 Mar;160(3):520-2. PubMed PMID:

22244459. PMCID: PMC3306811. Epub 2012/01/13. eng.

70. Smith RL, Sundberg J, Shamiyah E, Dyer A, Pachman LM. Skin involvement in juvenile dermatomyositis is associated with loss of end row nailfold capillary loops. J Rheumatol. 2004 Aug;31(8):1644-9. PubMed PMID: 15290747. eng.

71. Piotto DG, Len CA, Hilário MO, Terreri MT. Nailfold capillaroscopy in children and adolescents with rheumatic diseases. Rev Bras Reumatol. 2012 Oct;52(5):72232. PubMed PMID: 23090372. eng|por.

72. Schmeling H, Stephens S, Goia C, Manlhiot C, Schneider R, Luthra S, et al. Nailfold capillary density is importantly associated over time with muscle and skin disease activity in juvenile dermatomyositis. Rheumatology (Oxford). 2011 May;50(5):885-93. PubMed PMID: 21156669. Epub 2010/12/13. eng.

73. Reed AM, Peterson E, Bilgic H, Ytterberg SR, Amin S, Hein MS, et al. Changes in novel biomarkers of disease activity in juvenile and adult dermatomyositis are sensitive biomarkers of disease course. Arthritis Rheum. 2012 Dec;64(12):4078-86. PubMed PMID: 22886447. PMCID: PMC3510329. eng. 74. Davis WR, Halls JE, Offiah AC, Pilkington C, Owens CM, Rosendahl K. Assessment of active inflammation in juvenile dermatomyositis: a novel magnetic 
resonance imaging-based scoring system. Rheumatology (Oxford). 2011

Dec;50(12):2237-44. PubMed PMID: 21972421. Epub 2011/10/04. eng.

75. Luca NJ, Feldman BM. Disease activity measures in paediatric rheumatic diseases. Int J Rheumatol. 2013;2013:715352. PubMed PMID: 24089617. PMCID: PMC3781994. Epub 2013/09/08. eng.

76. Rider LG, Aggarwal R, Pistorio A, Bayat N, Erman B, Feldman BM, et al. 2016 American College of Rheumatology/European League Against Rheumatism Criteria for Minimal, Moderate, and Major Clinical Response in Juvenile Dermatomyositis: An International Myositis Assessment and Clinical Studies Group/Paediatric Rheumatology International Trials Organisation Collaborative Initiative. Ann Rheum Dis. 2017 May;76(5):782-91. PubMed PMID: 28385804. PMCID: PMC5517365. eng.

77. Rider LG, Werth VP, Huber AM, Alexanderson H, Rao AP, Ruperto N, et al. Measures of adult and juvenile dermatomyositis, polymyositis, and inclusion body myositis: Physician and Patient/Parent Global Activity, Manual Muscle Testing (MMT), Health Assessment Questionnaire (HAQ)/Childhood Health Assessment Questionnaire (C-HAQ), Childhood Myositis Assessment Scale (CMAS), Myositis Disease Activity Assessment Tool (MDAAT), Disease Activity Score (DAS), Short Form 36 (SF-36), Child Health Questionnaire (CHQ), physician global damage, Myositis Damage Index (MDI), Quantitative Muscle Testing (QMT), Myositis Functional Index-2 (FI-2), Myositis Activities Profile (MAP), Inclusion Body Myositis Functional Rating Scale (IBMFRS), Cutaneous Dermatomyositis Disease Area and Severity Index (CDASI), Cutaneous Assessment Tool (CAT), Dermatomyositis Skin Severity Index (DSSI), Skindex, 
and Dermatology Life Quality Index (DLQI). Arthritis Care Res (Hoboken). 2011 Nov;63 Suppl 11:S118-57. PubMed PMID: 22588740. PMCID: PMC3748930. eng.

78. Quiñones R, Morgan GA, Amoruso M, Field R, Huang CC, Pachman LM. Lack of achievement of a full score on the childhood myositis assessment scale by healthy four-year-olds and those recovering from juvenile dermatomyositis. Arthritis Care Res (Hoboken). 2013 Oct;65(10):1697-701. PubMed PMID: 23666925. eng. 79. Rennebohm RM, Jones K, Huber AM, Ballinger SH, Bowyer SL, Feldman BM, et al. Normal scores for nine maneuvers of the Childhood Myositis Assessment Scale. Arthritis Rheum. 2004 Jun;51(3):365-70. PubMed PMID: 15188320. eng. 80. Rider LG, Koziol D, Giannini EH, Jain MS, Smith MR, Whitney-Mahoney K, et al. Validation of manual muscle testing and a subset of eight muscles for adult and juvenile idiopathic inflammatory myopathies. Arthritis Care Res (Hoboken). 2010 Apr;62(4):465-72. PubMed PMID: 20391500. PMCID: PMC2924143. eng. 81. Huber AM, Lachenbruch PA, Dugan EM, Miller FW, Rider LG, Group JDDACS. Alternative scoring of the Cutaneous Assessment Tool in juvenile dermatomyositis: results using abbreviated formats. Arthritis Rheum. 2008 Mar;59(3):352-6. PubMed PMID: 18311761. PMCID: PMC2598766. eng. 82. Campanilho-Marques R, Almeida B, Deakin C, Arnold K, Gallot N, de lorio M, et al. Comparison of the Utility and Validity of Three Scoring Tools to Measure Skin Involvement in Patients With Juvenile Dermatomyositis. Arthritis Care Res (Hoboken). 2016 Oct;68(10):1514-21. PubMed PMID: 26881696. PMCID: PMC5053292. Epub 2016/09/16. eng.

83. Tiao J, Feng R, Berger EM, Brandsema JF, Coughlin CC, Khan N, et al. Evaluation of the reliability of the Cutaneous Dermatomyositis Disease Area and Severity Index and the Cutaneous Assessment Tool-Binary Method in juvenile 
dermatomyositis among paediatric dermatologists, rheumatologists and neurologists. Br J Dermatol. 2017 Apr. PubMed PMID: 28421601. Epub 2017/04/19. eng.

84. Rider LG, Feldman BM, Perez MD, Rennebohm RM, Lindsley CB, Zemel LS, et al. Development of validated disease activity and damage indices for the juvenile idiopathic inflammatory myopathies: I. Physician, parent, and patient global assessments. Juvenile Dermatomyositis Disease Activity Collaborative Study Group. Arthritis Rheum. 1997 Nov;40(11):1976-83. PubMed PMID: 9365086. eng.

85. Huber AM, Hicks JE, Lachenbruch PA, Perez MD, Zemel LS, Rennebohm RM, et al. Validation of the Childhood Health Assessment Questionnaire in the juvenile idiopathic myopathies. Juvenile Dermatomyositis Disease Activity Collaborative Study Group. J Rheumatol. 2001 May;28(5):1106-11. PubMed PMID: 11361197. eng.

86. Varnier GC, Ferrari C, Consolaro A, Marafon D, Pilkington C, Maillard S, et al. Introducing a new approach to clinical care of juvenile dermatomyositis: the juvenile dermatomyositis multidimensional assessment report [abstract]. Pediatric Rheumatology; 2013. p. 25.

87. Lazarevic D, Pistorio A, Palmisani E, Miettunen P, Ravelli A, Pilkington C, et al. The PRINTO criteria for clinically inactive disease in juvenile dermatomyositis. Ann Rheum Dis. 2013 May;72(5):686-93. PubMed PMID: 22736096. PMCID: PMC5040631. Epub 2012/06/26. eng.

88. Almeida B, Campanilho-Marques R, Arnold K, Pilkington CA, Wedderburn LR, Nistala K, et al. Analysis of Published Criteria for Clinically Inactive Disease in a Large Juvenile Dermatomyositis Cohort Shows That Skin Disease Is Underestimated. Arthritis Rheumatol. 2015 Sep;67(9):2495-502. PubMed PMID: 25988361. PMCID: PMC4737199. eng. 
89. McCann L, Pilkington C, Huber A, Ravelli A, Appelbe D, Kirkham J, et al. The development of a consensus dataset in Juvenile Dermatomyositis for clinical use to inform research. Annals Rheum Dis 2017;('In Press').

90. Lundberg IE, Svensson J. Registries in idiopathic inflammatory myopathies. Curr Opin Rheumatol. 2013 Nov;25(6):729-34. PubMed PMID: 24047606. eng. 91. Rider LG, Dankó K, Miller FW. Myositis registries and biorepositories: powerful tools to advance clinical, epidemiologic and pathogenic research. Curr Opin Rheumatol. 2014 Nov;26(6):724-41. PubMed PMID: 25225838. PMCID: PMC5081267. eng.

92. Martin N, Krol P, Smith S, Murray K, Pilkington CA, Davidson JE, et al. A national registry for juvenile dermatomyositis and other paediatric idiopathic inflammatory myopathies: 10 years' experience; the Juvenile Dermatomyositis National (UK and Ireland) Cohort Biomarker Study and Repository for Idiopathic Inflammatory Myopathies. Rheumatology (Oxford). 2011 Jan;50(1):137-45. PubMed PMID: 20823094. PMCID: PMC2999955. Epub 2010/09/07. eng.

93. Lilleker JB, Vencovsky J, Wang G, Wedderburn LR, Diederichsen LP, Schmidt J, et al. The EuroMyositis registry: an international collaborative tool to facilitate myositis research. Ann Rheum Dis. 2017 Aug. PubMed PMID: 28855174. Epub 2017/08/30. eng.

94. van Dijkhuizen EP, Deakin CT, Wedderburn LR, De lorio M. Modelling disease activity in juvenile dermatomyositis: A Bayesian approach. Stat Methods Med Res. 2017 Jan:962280217713233. PubMed PMID: 28589751. Epub 2017/01/01. eng. 


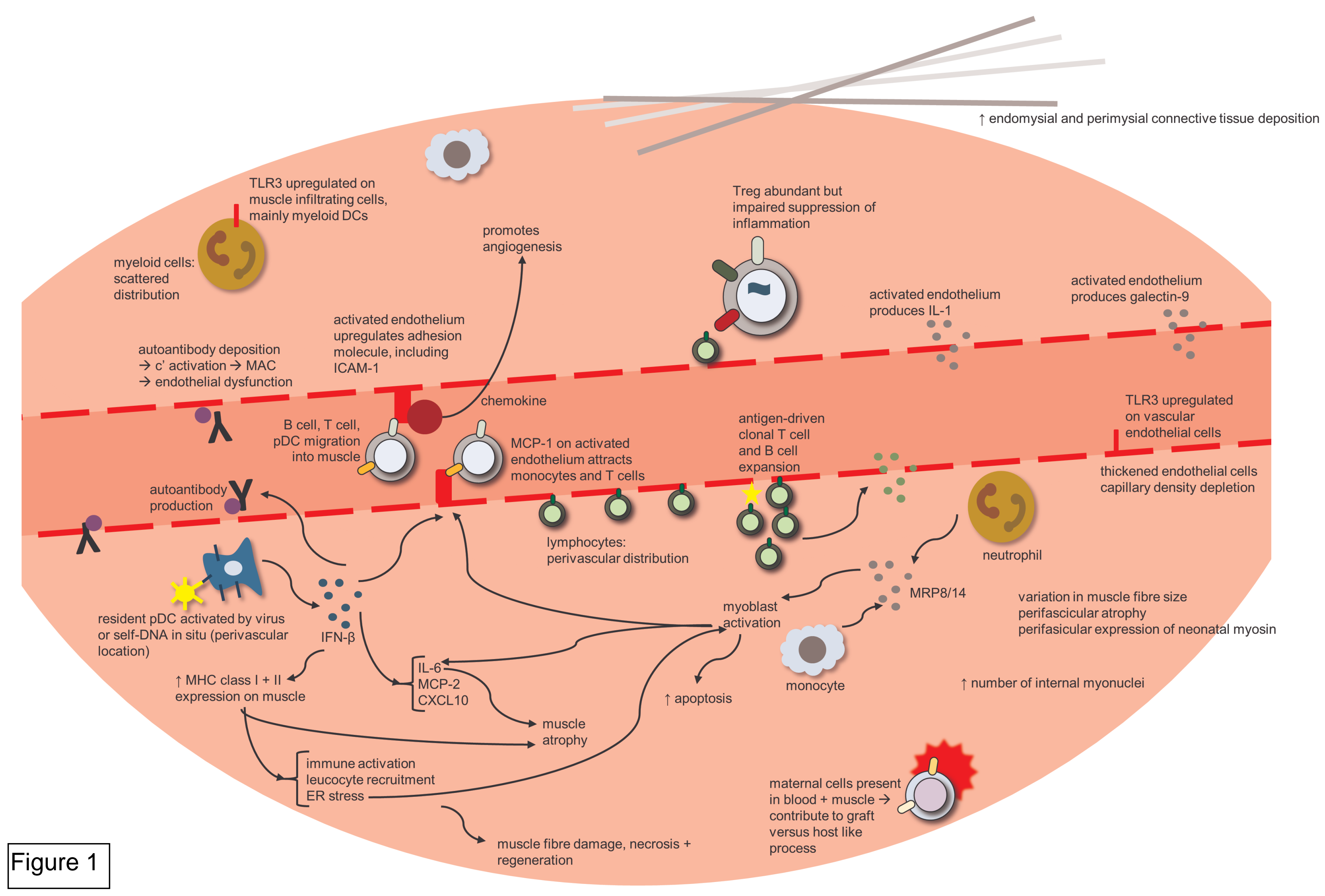


+ sun protection + adequate calcium/vitamin D intake

+ / change to cyclophosphamide IV 500-1000 $/ \mathrm{m}^{2}$ monthly for 3-6 months

OR + rituximab

OR change to infliximab / adalimumab

OR combination therapy with high dose MTX + ciclosporin A + IVIG

\section{regular reviews}

no improvement

$\downarrow$

OR change

OR change to infliximab /

Or combination therapy with

MTX, ciclosporin A +IVIG

\section{$\downarrow$}

regular reviews

no improvement $\quad$ improvement

check adherence +

treatment tolerance reduce / stop when remission $\geq 1 \mathrm{yr}$ off

steroids

Iimprovement improvement improvement

continue MTX wean steroids stop cyclophosphamide

stop when

remission $\geq 1 \mathrm{yr}$

off steroids

\section{regular reviews}

muscle strength

skin disease

major organ involvement

patient / parent reported outcome measures

no improvement

check adherence + treatment tolerance

+ IVIG

OR add or change to ciclosporin A

OR add or change to MMF

OR add or change to rituximab /

infliximab / adalimumab

\section{$\downarrow$}

regular reviews

no improvement

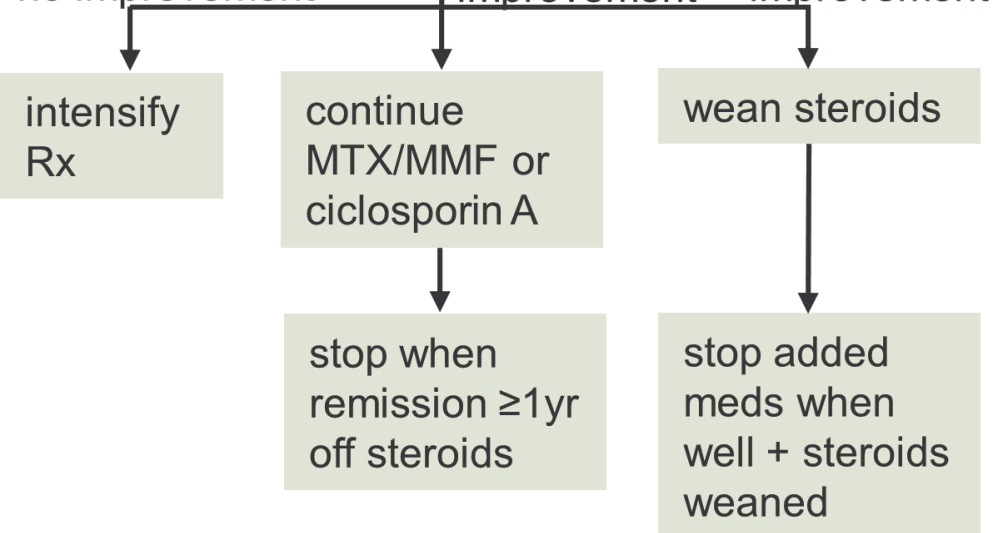

weaned improvement improvement intolerance

change to

MMF or

ciclosporin A

stop when

remission $\geq 1 \mathrm{y}$

off steroids 
- GI vasculitis (imaging / bloody stools)

- PGA of moderate disease on scale of mild / moderate / severe

- other autoimmune/mimicking disease

- requires ICU

- aspiration / dysphagia leading to inability to swallow

- CNS disease ( $\downarrow$ consciousness / seizures)

- skin ulceration

- medication contraindication

- myocarditis

- pregnancy

- significant calcinosis

<1year of age

choose one of

\section{plan A}

- MP IV $30 \mathrm{mg} / \mathrm{kg} /$ day $(\max 1 \mathrm{~g}$ ) for 3 days $\rightarrow$ then once/week (optional)

- prednisolone PO $2 \mathrm{mg} / \mathrm{kg} /$ day (max $60 \mathrm{mg}$ ) once/day for 4 weeks $\rightarrow$ then decrease by $20 \%$

- MTX SC lesser of $15 \mathrm{mg} / \mathrm{m}^{2}$ OR $1 \mathrm{mg} / \mathrm{kg}$ (max $40 \mathrm{mg}$ ) once/week

\section{plan B}

- MP IV $30 \mathrm{mg} / \mathrm{kg} /$ day $(\max 1 \mathrm{~g}$ ) for 3 days $\rightarrow$ then once/week (optional)

- prednisolone PO $2 \mathrm{mg} / \mathrm{kg} /$ day (max $60 \mathrm{mg}$ ) once/day for 4 weeks $\rightarrow$ then decrease by $20 \%$

- MTX SC lesser of $15 \mathrm{mg} / \mathrm{m}^{2}$ OR $1 \mathrm{mg} / \mathrm{kg}$ (max $40 \mathrm{mg}$ ) once/week

- IVIG $2 \mathrm{~g} / \mathrm{kg}$ (max $70 \mathrm{~g}$ ) once every 2 weeks for 3 cycles $\rightarrow$ then once monthly

+/- MP IV with each dose

\section{plan C}

- prednisolone PO $2 \mathrm{mg} / \mathrm{kg} /$ day (max $60 \mathrm{mg}$ ) divided twice/day for 4 weeks $\rightarrow$ then once/day

- MTX SC lesser of $15 \mathrm{mg} / \mathrm{m}^{2}$ OR $1 \mathrm{mg} / \mathrm{kg}$ (max $40 \mathrm{mg}$ ) once/week

assess disease in 4 weeks (strength, enzymes, rash)

worsened
escalate therapy further $\rightarrow$
consider adding:
$\cdot$ MP IV $20-30 \mathrm{mg} / \mathrm{kg}$
$\cdot+/$ immune modulatory agent
$\cdot$ IVIG
- ciclosporin
$\cdot$ MMF
$\cdot$ AZA
$\cdot$ biologic

\section{reassess in 4 weeks}

unchanged

improved

\section{improved}

hold medication stable

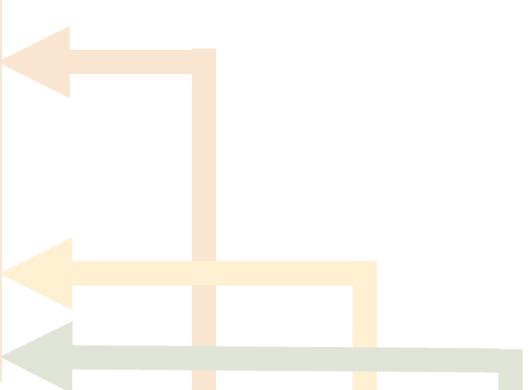

\section{reassess in 4 weeks}

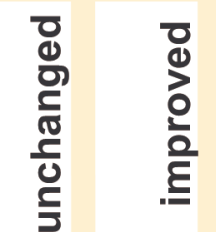

assess in 4

Figure 3

worsened

wean prednisolone:

- $2 \mathrm{mg} / \mathrm{kg}$ at 0 weeks

- $1.5 \mathrm{mg} / \mathrm{kg}$ at 8 weeks

- $1.0 \mathrm{mg} / \mathrm{kg}$ at 14 weeks

$0.5 \mathrm{mg} / \mathrm{kg}$ at 22 weeks

$0.2 \mathrm{mg} / \mathrm{kg}$ at 36 weeks

- stop at 50 weeks significant adverse

event or intolerance

dose reduction or discontinuation of

medication 
Table 1. Risk and protective alleles for juvenile dermatomyositis. $(3,4)$

\begin{tabular}{lll}
\hline Risk alleles & Alleles associated with more severe & Protective alleles \\
& disease & \\
\hline HLA-B ${ }^{*} 08$ & TNFa-308A & HLA-DQA1*0201 \\
HLA-DRB1*0301 & IL-1a-889C & HLA-DQA1*0101 \\
HLA-DQA1*0501 & HLA-DQA1*0102 \\
HLA-DPB1*0101 & \\
HLA-DQA1*0301 & \\
TNFa-238GG & \\
TNFa-308AG & \\
IL-1a+4845TT & \\
IL-1 $3+3953 T$ & \\
IgH (1,3,5,13,17,21,23) & \\
Ptpn22 (rs2476601) & \\
CCL21 (rs951005) & \\
PLCL1 (rs6738825) & \\
BLK (rs2736340) & \\
\hline HLA: human leucocyte antigen; TNF: tumour necrosis factor; IL: interleukin; IgH: immunoglobulin heavy chain; \\
Ptpn: protein tyrosine phosphatase; CCL: chemokine c-c motif ligand; PLCL: phospholipase c-like; BLK: B \\
lymphoid kinase
\end{tabular}


Table 2. Autoantibodies identified in juvenile dermatomyosistis and associated phenotypes and alleles. (4-7)

$\begin{array}{llll}\text { Autoantibody } & \text { Autoantigen target } & \text { Frequency in juvenile population } & \text { Clinical features in juvenile population }\end{array}$

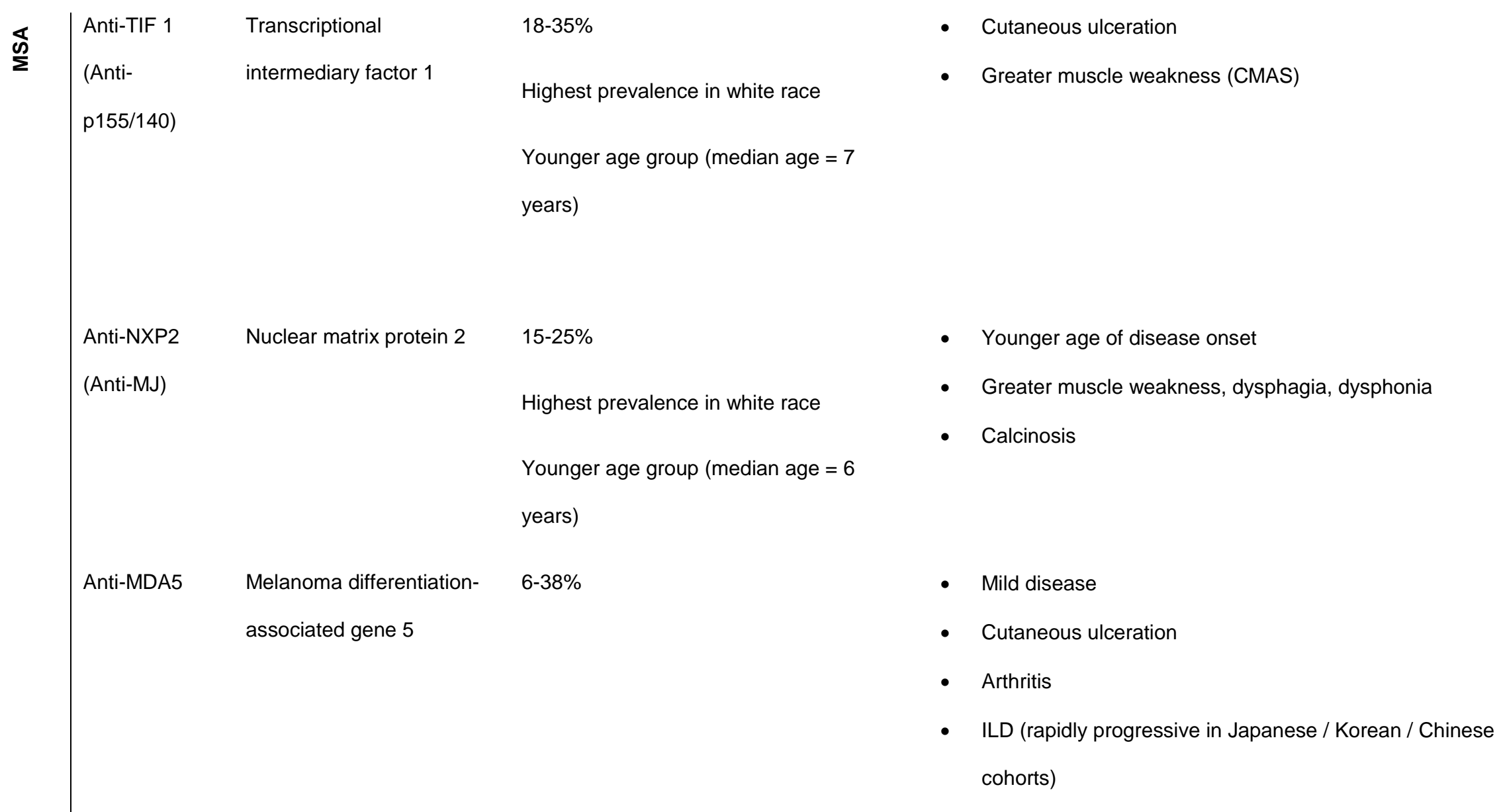




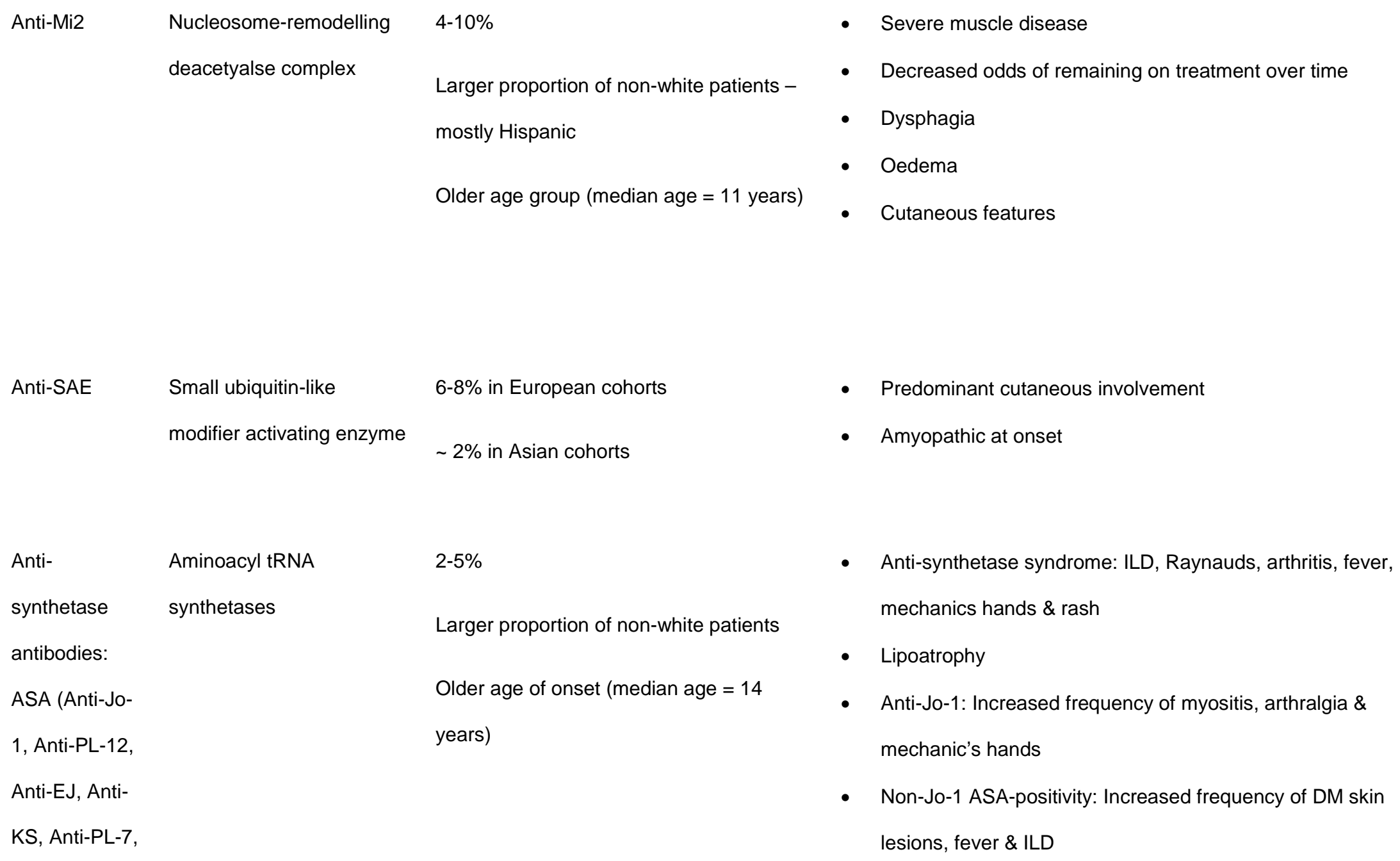

- Decreased odds of remaining on treatment over time

- Dysphagia

- Oedema

- Cutaneous features

Anti-SAE

Small ubiquitin-like modifier activating enzyme

Anti-

synthetase

antibodies:

ASA (Anti-Jo-

1, Anti-PL-12,

Anti-EJ, Anti-

KS, Anti-PL-7,

$6-8 \%$ in European cohorts

$\sim 2 \%$ in Asian cohorts

$2-5 \%$

Larger proportion of non-white patients

Older age of onset $($ median age $=14$

years)

- Predominant cutaneous involvement

- Amyopathic at onset

- Anti-synthetase syndrome: ILD, Raynauds, arthritis, fever, mechanics hands \& rash

- Lipoatrophy

- Anti-Jo-1: Increased frequency of myositis, arthralgia \& mechanic's hands

- Non-Jo-1 ASA-positivity: Increased frequency of DM skin lesions, fever \& ILD

Anti-OJ, Anti- 
Ha, Anti-Zo)

Anti-SRP Signal recognition particle $2 \%$ JDM

Increased prevalence in Black race

Older age of onset $($ median age $=15$

years)

Anti-HMGCR 3-hydroxy-3-methylglutaryl- $\quad$ 1\% JDM

coenzyme $\mathrm{A}$ reductase
- More likely to be classified as JPM

- $\quad$ Severe necrotising myopathy

- Chronic disease course

- More likely to be classified as JPM

- Increased risk of muscle weakness, \& dysphagia

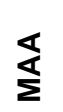

Anti-Ro (SSA)

\begin{abstract}
52 or $60 \mathrm{Kd}$
ribonucleoproteins
\end{abstract}

(hYRNA)
$6 \%$ JDM

14-25\% myositis overlap
- Associated with poorer prognosis with decreased functional status with long-term follow up 


\begin{tabular}{|c|c|c|c|}
\hline Anti-La (SSB) & Ribonucleoprotein & $2-12 \%$ myositis overlap & - No significant associations described in IIM \\
\hline Anti-U1-RNP & $\begin{array}{l}\text { U1 ribonucleoprotein } \\
\text { (snRNP) }\end{array}$ & $\begin{array}{l}\text { 3-8\% JDM / JPM } \\
25-40 \% \text { myositis overlap }\end{array}$ & $\begin{array}{l}\text { - Polymyositis / polymyositis overlap phenotype } \\
\text { - Older age at disease onset. Less likely to be weak }\end{array}$ \\
\hline Anti PM-Scl & $\begin{array}{l}\text { Nucleolar multi-protein } \\
\text { complex }\end{array}$ & $3-5 \%$ & $\begin{array}{l}\text { - Myositis overlap, most commonly scleroderma overlap } \\
\text { features } \\
\text { - } \quad \text { Risk of ILD, arthritis, Raynaud's } \\
\text { - } \\
\text { Association described with calcinosis \& lipoatrophy }\end{array}$ \\
\hline Anti-Ku & $\begin{array}{l}\text { p70/p80 heterodimer, } \\
\text { DNA-associated proteins }\end{array}$ & 9-19\% pateints with myositis overlap & $\begin{array}{l}\text { - } \quad \text { CTD overlap } \\
\text { - Increased arthralgia, Raynaud's, ILD \& musculoskeletal } \\
\text { manifestations }\end{array}$ \\
\hline
\end{tabular}

MSA: myositis specific antibodies; MAA: myositis associated antibodies; ILD: interstitial lung disease; IIM: idiopathic inflammatory myopathies; JPM: juvenile polymyositis; JDM: juvenile dermatomyositis 
Table 3. Muscle biopsy features and associated phenotype. $(10,11)$

\begin{tabular}{ll}
\hline Muscle biopsy & Clinical features \\
\hline Lymphoid follicles including networks of fDCs and high endothelial & Severe disease course \\
venules & \\
High levels of CXCL13 and lymphotoxins & \\
Resident naive CD45RA+ T cells and maternally derived B cells and & \\
pDCs & Chronic disease course with \\
Severe arteriopathic changes & ulceration \\
Positive arterial direct immunofluorescence & \\
Severe capillary loss & \\
Endomysial fibrosis & \\
Muscle infarcts & Chronic disease course \\
Extensive active myopathic changes & \\
Central nuclei without basophilia & \\
\hline
\end{tabular}

fDC: follicular dendritic cells; CXCL13: C-X-C Motif Chemokine Ligand 13; pDC: plasmacytoid dendritic cells 
Table 4. Drug studies in patients with juvenile dermatomyositis. $(8,20)$

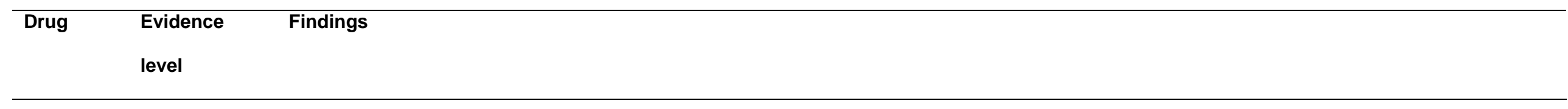

\section{CS}

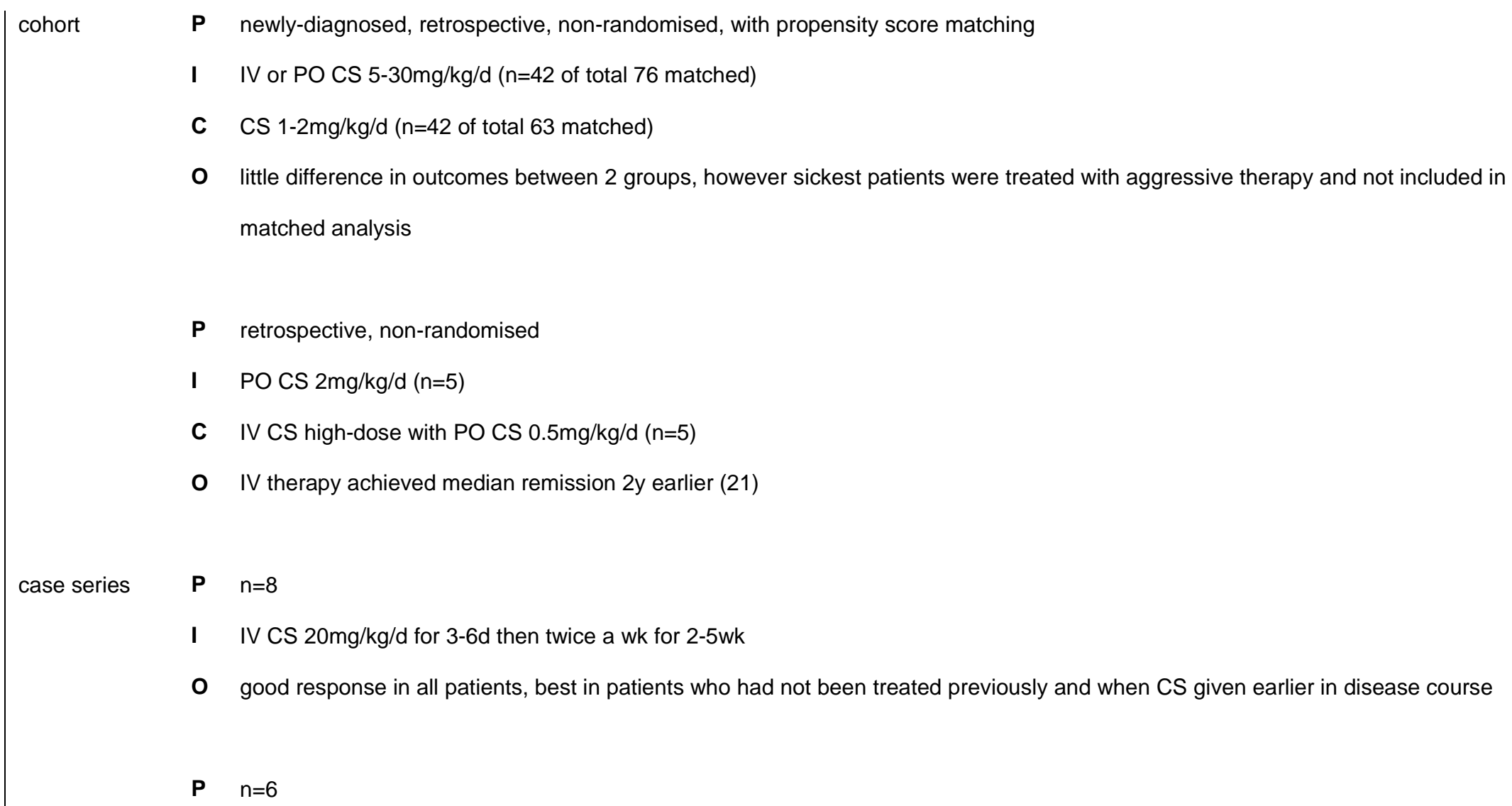

O little difference in outcomes between 2 groups, however sickest patients were treated with aggressive therapy and not included in matched analysis

P retrospective, non-randomised

I PO CS $2 \mathrm{mg} / \mathrm{kg} / \mathrm{d}(\mathrm{n}=5)$

C IV CS high-dose with PO CS $0.5 \mathrm{mg} / \mathrm{kg} / \mathrm{d}(\mathrm{n}=5)$

- IV therapy achieved median remission 2y earlier (21)

P $\quad \mathrm{n}=8$

I IV CS $20 \mathrm{mg} / \mathrm{kg} / \mathrm{d}$ for 3-6d then twice a wk for $2-5 \mathrm{wk}$

O good response in all patients, best in patients who had not been treated previously and when CS given earlier in disease course

P $\quad \mathrm{n}=6$ 


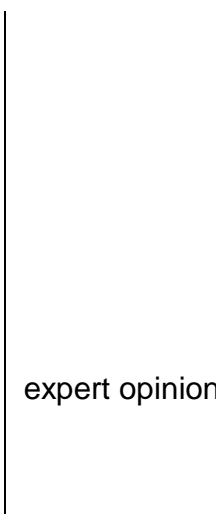

MTX

RCT

cohort

I PO CS $50 \mathrm{mg} / \mathrm{m}^{2}$ on $\mathrm{d} 1$

C IV CS on d 2

- AUC of IV CS greater than PO CS but not significant difference. Inverse association between difference of AUC between IV and PO CS and nailfold ERL

IV CS for 3-5d followed by PO CS $2 \mathrm{mg} / \mathrm{kg} / \mathrm{d}$ (single morning dose) has lesser effects on the hypothalamic-pituitary-adrenal function and growth

P newly-diagnosed, no previous treatment, no cutaneous / Gl ulceration

I prednisolone alone $(\mathrm{n}=47)$

C prednisone $+\operatorname{CiA}(n=46)$ OR prednisone $+\operatorname{MTX}(n=46)$

O at $6 \mathrm{mo}, 51 \%$ of prednisone, $70 \%$ of prednisone $+\mathrm{CiA}$, and $72 \%$ of prednisone $+\mathrm{MTX}$ achieved improvement. More patients on prednisone $+\mathrm{CiA}$ had adverse events. More patients in prednisone $+\mathrm{CiA}$ and prednisone + MTX had infections

P consecutive patients in clinic before and after date of new policy of first-line therapy with MTX, non-randomised, retrospective

IC MTX $10-20 \mathrm{mg} / \mathrm{m}^{2} / \mathrm{wk}+$ PO prednisolone $2 \mathrm{mg} / \mathrm{kg} / \mathrm{d}$, at 6 wks if muscle enzymes reduced + improved clinically, prednisone tapered by 10\%

O every 2 wks $(n=31)$

PO prednisolone $2 \mathrm{mg} / \mathrm{kg} / \mathrm{d}$, at 6 wks tapered by $\sim 10 \%$ every mo $(\mathrm{n}=22)$

study group had approximately half cumulative prednisolone dose, greater height velocity during $1^{\text {st }} \mathrm{yr}$ of treatment, smaller BMI increase in $1^{\text {st } 2}$ yrs, longer time to development of cataracts

P $n=16$, recalcitrant disease 
I MTX + PO prednisone

- all 12 patients who received MTX for at $\geq 8 \mathrm{mo}$ regained normal muscle strength. In $11 / 12$ patients, prednisone tapered to $\leq 5 \mathrm{mg} /$ day. Active disease occurred in 5 patients when MTX stopped after remission. Complications of MTX required discontinuation in 5 patients

$\mathbf{P} \quad \mathrm{n}=5$

I $\quad C S+\operatorname{MTX}(n=3)$ or CS $+\operatorname{MTX}+\operatorname{AZA}(n=2)$

- Clinical improvement in 4 patients. 1 patient continued to experience weakness and episode of pericarditis

P $\quad \mathrm{n}=4$

I 9-31mo with PO prednisolone + IV MTX

0 at $3 \mathrm{mo}$, clinical improvement + reduction of prednisolone dose. 3 patients recovered, 1 patient died. Adverse effects: elevated liver enzymes nausea, abdominal pain, bone pain, mild neutropenia, mild pruritis

see RCT in MTX above

case series

P $\quad \mathrm{n}=5(+17$ JIA patients)

I CiA mean dose $3.2 \mathrm{mg} / \mathrm{kg} / \mathrm{d}$ over mean period $16 \mathrm{mo}$

0 prednisone stopped in $5 / 20$ patients and reduced by $>50 \%$ in $10 / 20$ patients. No hepatic or bone marrow toxicity or lymphoproliferative disease

P $\quad \mathrm{n}=3$ (+9 JIA patients), not responded to CS +/or cytotoxics 
I CiA mean dose $5 \mathrm{mg} / \mathrm{kg} / \mathrm{d}$ over $9-48 \mathrm{mo}$

0 treatment effective. Adverse effects: alopecia, hypertension, hypertrichosis, tremors, hirsutism. 1 JIA patient developed polyserositis with hypoproteinemia of unknown origin

P $\quad \mathrm{n}=14$, not responded to CS + other immunosuppressants

CiA

O CS stopped or reduced in all patients. Regain of muscle strength and function. No serious adverse effects

- 6 patients showed good response. 1 complication observed: transient neutropenia

P $\quad \mathrm{n}=50$

I MMF for $12 \mathrm{mo}$

0 decrease in mean sDAS, mDAS, prednisone dosage. WBC count unchanged. No difference in infection rate between $12 \mathrm{mo}$ pre-treatment period and $1^{\text {st }} 6 \mathrm{mo}$ of MMF, infection rate decreased in $2^{\text {nd }} 6 \mathrm{mo}$ of MMF (infection rate studied in $\mathrm{n}=26$ subset who were observed for $12 \mathrm{mo}$ before start of MMF 
P Juvenile Dermatomyositis Cohort and Biomarker Study and Repository (UK and Ireland)

I CYC $500 \mathrm{mg} / \mathrm{m}^{2}$ every $2 \mathrm{wk}$ for $1^{\text {st }} 3$ doses then $750 \mathrm{mg} / \mathrm{m}^{2}$ every $3-4 \mathrm{wks}$ for total $6-10$ doses $(\mathrm{n}=83)$

C remaining patients (with less severe disease) in cohort did not receive CYC ( $n=442)$

0 at 24mo, improvement in PGA, mDAS, CMAS and MMT8. No serious adverse effects. Ongoing analyses on disease trajectories of patients treated with CYC and patients not treated with CYC

P $\quad \mathrm{n}=12$, severe and refractory disease

I $\quad$ CYC

O at $6 \mathrm{mo}, 83 \%$ had improved muscle function and strength, LDH, skin disease, global extramuscular disease. No severe adverse effects. Reversible complications: Iymphopenia, herpes zoster infection, alopecia. 2 patients with severe refractory disease died after 1 dose of CYC (thought to be result of severe disease)

P $\quad \mathrm{n}=9$, not responded to CS / exacerbation when tapering CS

I HCQ mean dose $3.6 \mathrm{mg} / \mathrm{kg} / \mathrm{d}$

0 at 3 mo, improvement in rash, proximal and abdominal muscle strength high dose + long duration of HCQ use are risks for ocular toxicity, maximum dose should be $\leq 5.0 \mathrm{mg} / \mathrm{kg} / \mathrm{d}$ real weight, annual screening recommended 
P $\quad \mathrm{n}=3$, refractory extensive skin disease, severe muscle weakness, CS dependent

I TAC

O improvement of cutaneous lesions, no improvement of muscle strength, overall disease activity decreased, tapering of CS dosage. No adverse effects.

P retrospective, marginal structural modelling to account for confounding by indication

I IVIG (these patients had weaker muscle strength and more photosensitivity) ( $n=30)$

C no IVIG $(\mathrm{n}=48)$

O IVIG patients had similar/lower disease activity compared to controls, improvement most marked in CS-resistant patients

P $\quad \mathrm{n}=9$, not responded / severe side effects to conventional treatment

I IVIG

- clinical improvement. Of 8 patients on prednisolone, dose reduced in 6 and kept same in 2

P $\quad \mathrm{n}=2$, refractory to CS with steroid toxicity

I IVIG

o clinical improvement 


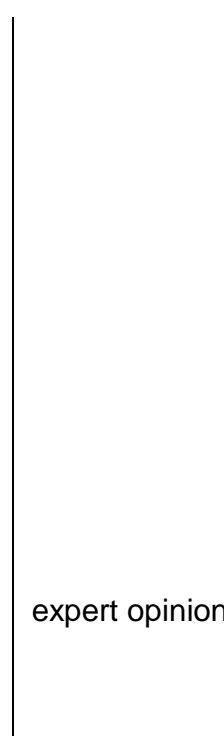

P $n=18$, not responded to IVIG or steroid toxicity

I IVIG

o 12 patients showed clinical improvement. CS dose was reduced by $>50 \%$ for $>3 \mathrm{mo}$

P n=5, not responded to CS / other immunosuppressive therapy toxicity

I IVIG

O improved muscle strength and skin rash. CS stopped or dose reduced

IVIG once every 2 wks for 3 cycles then monthly is the preferred regimen

RTX

$\mathrm{RC}$

P adults with refractory PM + adults and children with refractory DM

I $\operatorname{RTX}$ at wk $0(\mathrm{n}=93)$

C RTX at wk $8(n=102)$

- no difference in time to achieve IMACS group DOI between 2 groups. However, $83 \%$ patients with refractory disease met DOI

cohort

P retrospective analysis of RCT above

O anti-Jo-1 and anti-Mi-2 autoantibody predicted shorter time to improvement. JDM demonstrated trend toward better clinical improvement compared to adult subgroups $(\mathrm{p}=0.06)$ prior to wk 20

P $\quad \mathrm{n}=9$, severe +/or refractory muscle involvement, severe calcinosis, abdominal lipomatosis 
I RTX

- complete response achieved in $3 / 6$ patients treated for muscle involvement, where CS stopped or tapered to $<15 \%$ of baseline. No improvement in calcinosis. Complications: mild infections of calcinosis sites $(n=2)$, infusion-related event $(n=1)$

P Juvenile Dermatomyositis Cohort and Biomarker Study and Repository (UK and Ireland)

I anti-TNF agents $(\mathrm{n}=66)$

0 improvement in muscle and skin disease. 21 adverse effects (including 7 severe = anaphylaxis on IFX). 1 patient died due to small bowel perforation (not felt to be related to use of anti-TNF). $77 \%$ of non-severe adverse reactions were due to infections (no TB)

P $n=5$, refractory disease

I IFX IV 3mg/kg at 0, 2, 6, 8wks

0 improvements in pVAS, CMAS, CHAQ, joint range of movement. In some children, regression of calcinosis and skin signs. No major adverse effects 
I ETN $0.4 \mathrm{mg} / \mathrm{kg} \mathrm{SC}$ twice weekly for 12 wks and followed up for 12 wks after last dose ETN

- At 24wks, 1 patient stable, 2 patients had worsening DAS, 3 patients had improved DAS. Trend of worsening NFC at wk 12 and improvement at wk 24. No change in muscle enzymes or CMAS. 1 patient stopped after $5^{\text {th }}$ ETN dose (marked worsening of rash).

P: population; I: intervention; C: comparison; O: outcome; RCT: randomised controlled trial; CS: corticosteroid; IV: intravenous; PO: oral; d: day; yr: year; wk: week; AUC: area under curve; ERL: end row loops; MTX: methotrexate; CiA: ciclosporin; mo: month; BMI: body mass index; AZA: azathioprine; JIA: juvenile idiopathic arthritis; MMF: mycophenolate mofetil; sDAS: skin disease activity score; mDAS: muscle disease activity score; WBC: white blood cell; PGA: physician global assessment; CMAS: childhood myositis assessment score; MMT8: manual muscle testing 8; CYC:

cyclophosphamide; LDH: lactate dehydrogenase; HCQ: hydroxychloroquine; TAC: tacrolimus; IVIG: intravenous immunoglobulin; RTX: rituximab; IMACS: International Myositis Assessment and

Clinical Studies Group; DOI: definition of improvement; JDM: juvenile dermatomyositis; IFX: infliximab; pVAS: physician visual analogue scale; CHAQ: childhood health assessment questionnaire;

ADA: adalimumab; ETN: etanercept; SC: subcutaneous; NFC: nailfold capillary 
Table 5. Comparison of Paediatric Rheumatology International Trials Organisation and International Myositis Assessment and Clinical Studies Group core response variables. (76)

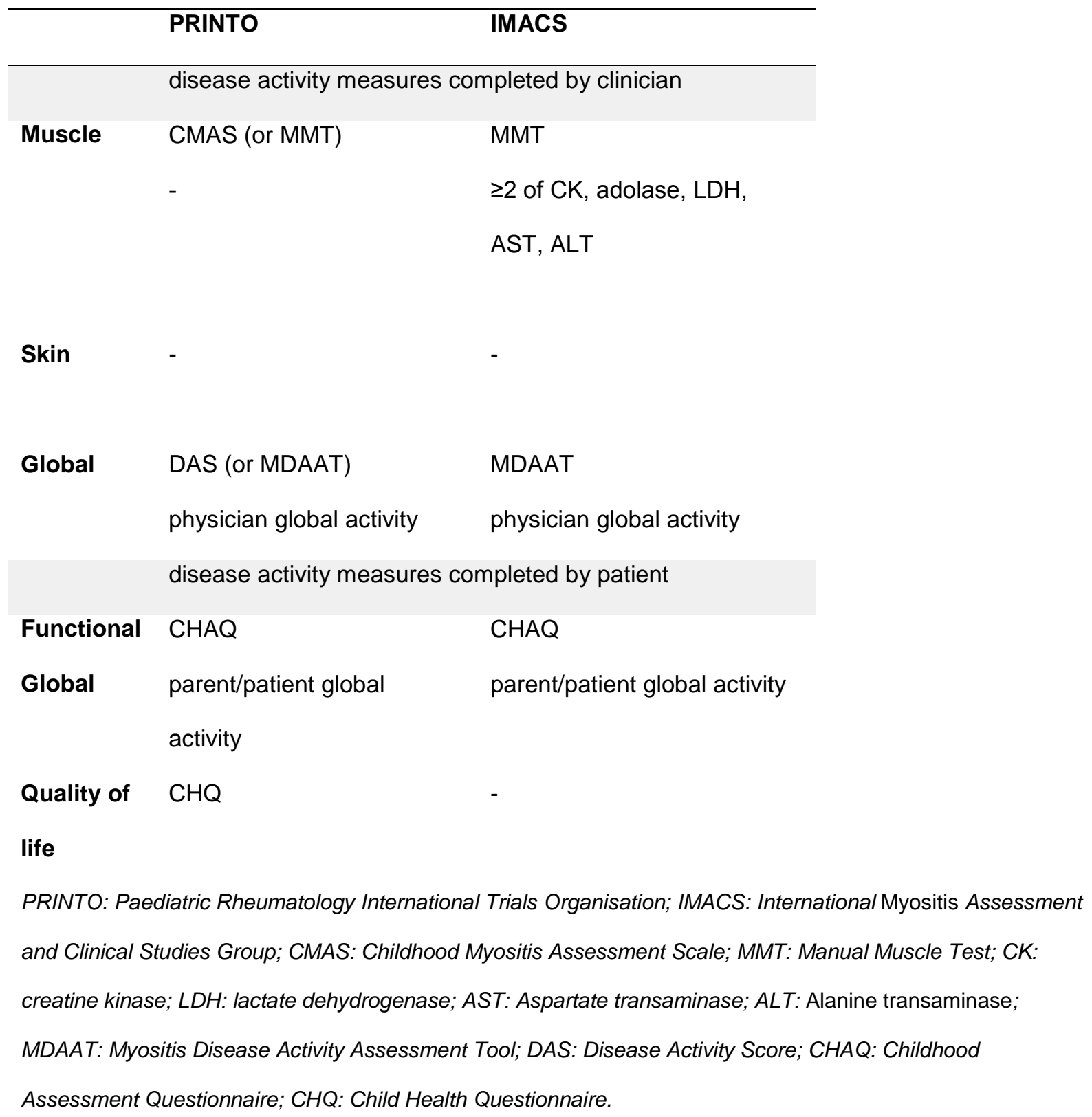

